Check for updates

Cite this: RSC Adv., 2018, 8, 23854

Received 12th May 2018

Accepted 15th June 2018

DOI: $10.1039 / c 8 r a 04052 d$

rsc.li/rsc-advances

\section{Synthesis of arrays containing porphyrin, chlorin, and perylene-imide constituents for panchromatic light-harvesting and charge separation $\uparrow$}

\author{
Gongfang Hu, (D) ${ }^{a}$ Hyun Suk Kang, (D) ${ }^{b}$ Amit Kumar Mandal, (D) ${ }^{b}$ Arpita Roy, (D) ${ }^{\text {b }}$ \\ Christine Kirmaier, (D) ${ }^{b}$ David F. Bocian, (iD *c Dewey Holten (iD *b \\ and Jonathan S. Lindsey (iD *a
}

\begin{abstract}
Achieving solar light harvesting followed by efficient charge separation and transport is an essential objective of molecular-based artificial photosynthesis. Architectures that afford strong absorption across the near-UV to near-infrared region, namely panchromatic absorptivity, are critically important given the broad spectral distribution of sunlight. A tetrapyrrole-perylene pentad array was synthesized and investigated as a means to integrate panchromatic light harvesting and intramolecular charge separation. The pentad consists of three moieties: (1) a panchromatically absorbing triad, in which a porphyrin is strongly coupled to two perylene-monoimides via ethyne linkages; (2) a perylene-diimide electron acceptor; and (3) a chlorin hole-trapping unit. Integrating the three components with diphenylethyne linkers generates moderate electronic coupling for intramolecular energy and hole/electron transfer. The construction of the array relies on a stepwise strategy for incorporating modular pigment building blocks. The key building blocks include a trans- $\mathrm{A}_{2} \mathrm{BC}$ porphyrin, a chlorin, a perylene-monoimide, and a perylene-diimide, each bearing appropriate (halo, ethynyl) synthetic handles for Pd-catalyzed Sonogashira coupling reactions. One target pentad, three tetrads, four triads, and four monomeric benchmark compounds were synthesized from six building blocks (three new, three reported) and 10 new synthetic intermediates. Four of the tetrapyrrole-containing arrays are zinc chelated, and four others are in the free base form. Absorption and fluorescence spectra and fluorescence quantum yields were also measured. Collectively, investigations of the arrays reveal insights into principles for the design of novel reaction centers integrated with a panchromatic antenna for artificial photosynthetic studies.
\end{abstract}

\section{Introduction}

A chief objective of artificial photosynthesis is to create model systems that mimic native photosynthetic processes and through systematic modifications can be used to probe relevant physicochemical features. The processes encompass diverse phenomena including light capture, excited-state energy transfer, excited-state electron transfer, dark electron/hole transfer, proton pumping, carbon fixation, and water splitting. While early model systems were first reported decades ago, ${ }^{1-12}$ the ensuing half-century of research has not resolved

\footnotetext{
${ }^{a}$ Department of Chemistry, North Carolina State University, Raleigh, North Carolina 27695-8204, USA. E-mail: jlindsey@ncsu.edu; Tel: +1-919-515-6406

${ }^{b}$ Department of Chemistry, Washington University, St. Louis, Missouri, 63130-4889, USA. E-mail: holten@wustl.edu; Tel: +1-314-935-6502

${ }^{c}$ Department of Chemistry, University of California, Riverside, California 92521-0403, USA. E-mail: david.bocian@ucr.edu; Tel: +1-951-827-3660

$\dagger$ Electronic supplementary information (ESI) available: NMR spectra for all new compounds; MALDI-MS data and analytical SEC traces for all arrays and benchmarks; and reaction monitoring by analytical SEC for C-T-PDI. See DOI: 10.1039/c8ra04052d
}

fundamental synthetic limitations to the creation of molecular architectures that rival those in native photosynthesis. Such architectures require large numbers of pigments and redox cofactors organized in exacting 3-dimensional spatial arrangements over mesoscale dimensions. Given the challenges of creating such architectures, an alternative tack entails development of more compact structures with designs complementary to those in native photosynthesis. ${ }^{13-27}$

As one case in point, we recently developed a design motif that engenders panchromatic absorption yet affords a lowest singlet excited-state of discrete energy. ${ }^{28,29}$ The motif relies on a perylene-monoimide attached to a porphyrin via an ethyne linker, where the linker joins the perylene 9-position and the porphyrin meso-position, both of which are sites of high electron density in the highest occupied molecular orbital (HOMO) of each constituent. Such a triad $\left(\mathbf{P M I}_{2 \mathbf{T}} \mathbf{P}\right)$ composed of two perylene-monoimides tightly coupled electronically (via ethyne linkers) to one porphyrin is shown in Fig. $1 .^{29}$ The triad absorbs strongly across the 400-700 $\mathrm{nm}$ region (average peak $\varepsilon \sim$ $80000 \mathrm{M}^{-1} \mathrm{~cm}^{-1}$ ), yet exhibits excited-state features similar to those of the tetrapyrrole Indeed, the fluorescence emission 


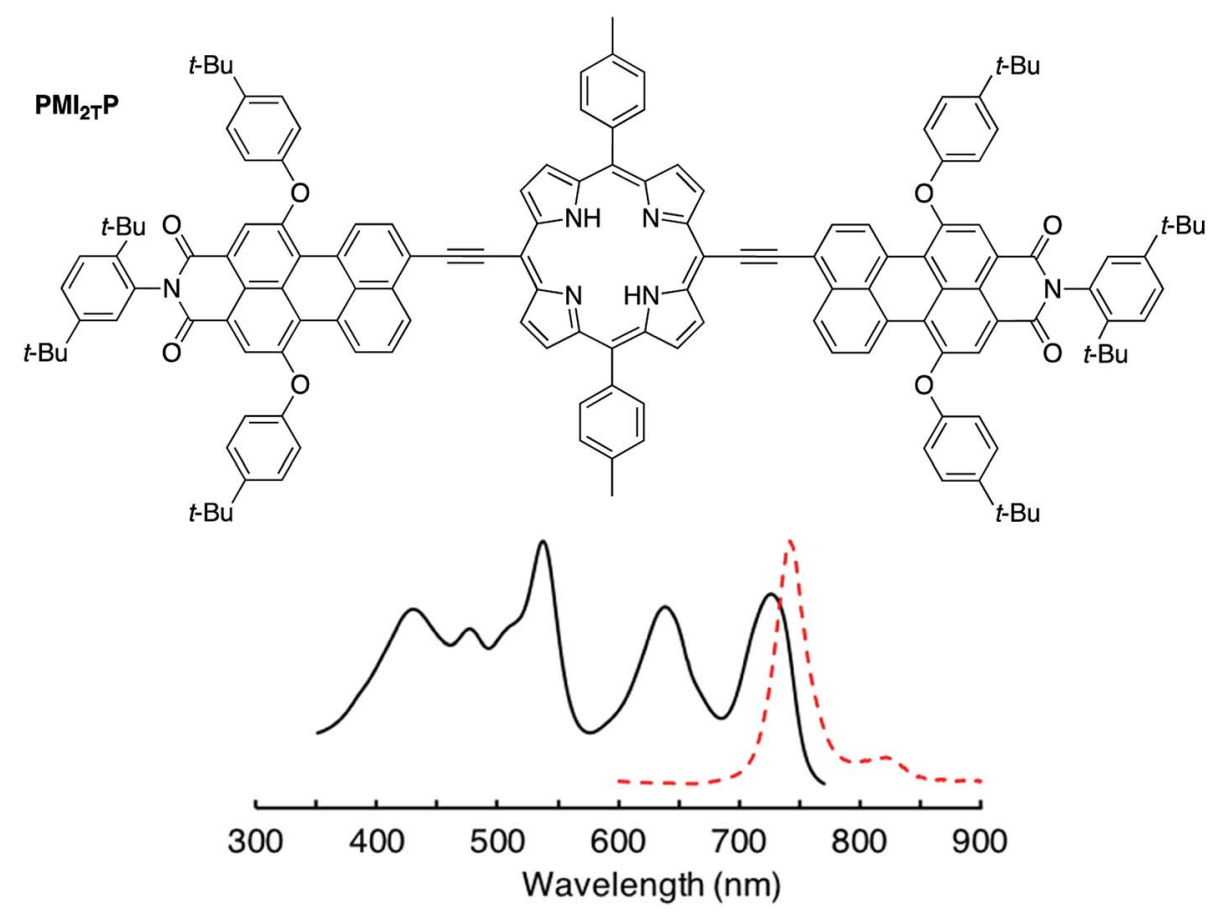

Fig. 1 The absorption (black solid) and fluorescence (red dashed) spectra of a prior panchromatic triad $\mathrm{PMI}_{2 \mathrm{~T}} \mathrm{P}$.

spectrum generally resembles that of a free base tetraarylporphyrin, although shifted bathochromically, and the fluorescence quantum yield $\left(\Phi_{\mathrm{f}}\right)$ is considerably enhanced versus that of the porphyrin alone. This latter effect arises from a dramatic shift in radiative probability from the normally intense porphyrin near-UV Soret band(s) to the normally weak porphyrin visible bands including the $S_{0} \rightarrow S_{1}$ absorption (and $\mathrm{S}_{1} \rightarrow \mathrm{S}_{0}$ fluorescence) transition. ${ }^{30}$ Because the triad exhibits tetrapyrrole-like lowest singlet excited-state properties we considered that the triad could be used as an antenna element in conjunction with an integrated charge-separation unit. The resulting integrated pentad array (C-T-PDI) contains a perylenemonoimide-porphyrin-perylene-monoimide triad unit $(\mathrm{T})$, a perylene-diimide (PDI), and a chlorin (C) (Chart 1).

The processes envisaged for light harvesting and charge separation in the pentad C-T-PDI are illustrated in Fig. 2. The central triad acts as a supermolecule with panchromatic absorption (see e.g. Fig. 1) as a result of the substantial electronic interactions between the porphyrin and perylenemonoimides afforded by the direct ethyne linkers. Excitation in any of the absorption bands of the triad is followed by rapid, quantitative energy flow to the tetrapyrrole-like lowest energy singlet excited state $\left(\mathrm{S}_{1}\right)$ of this array, analogous to internal conversion from upper to lower energy excited states of a simple chromophore. The core porphyrin is of a trans $-\mathrm{A}_{2} \mathrm{BC}$ design. The perylene-diimide and chlorin are each attached to the core porphyrin via a diphenylethyne linker, which affords electronic interactions that while weaker than a direct ethyne linkage, enable electronic coupling sufficient to support rapid energy and hole/electron transfer with only slight perturbation of energy levels and electronic spectra. The perylene-diimide serves as an acceptor upon excited-state electron transfer from the excited triad $\left(\mathrm{T}^{*}\right)$, whereas the chlorin functions as a hole trap via a ground-state process involving the oxidized triad $\left(\mathrm{T}^{+}\right)$. The overall light-driven process is thus expected to afford the chlorin cation radical and perylene-diimide anion radical upon charge separation across the pentad (forming $\mathrm{C}^{+}-\mathrm{T}-\mathrm{PDI}^{-}$). While the chief functions of the perylene-diimide and the chlorin are for charge separation, both also absorb light and are expected to afford additional light-harvesting capacity to the pentad by funneling harvested excitation energy to the $\mathrm{S}_{1}$ excited state of the central triad.

Herein, we report the synthesis of the pentad array as well as all companion arrays for full photophysical characterization. The synthesis relies on a building block approach ${ }^{31-34}$ wherein constituent chromophores are synthesized separately and then joined together through Pd-mediated coupling reactions. The companion arrays include three tetrads (Chart 2), four triads (Chart 3), and four monomeric compounds (Chart 4). The 12 targets (one pentad and 11 benchmark compounds) were prepared from six building blocks (three new, three reported) and 10 new synthetic intermediates. Absorption and fluorescence studies are also reported as a first step toward in-depth analysis of integrated light-harvesting and charge-separation processes in the arrays.

\section{Results and discussion}

\section{Molecular design}

The rationale for the selection of components of the pentad was based on optical and redox properties. In particular, a chlorin with sparse substitution ${ }^{35}$ was chosen given that such chlorins exhibit a wavelength absorption band at shorter wavelength, and thus an $S_{1}$ excited-state at higher energy, than that of the 


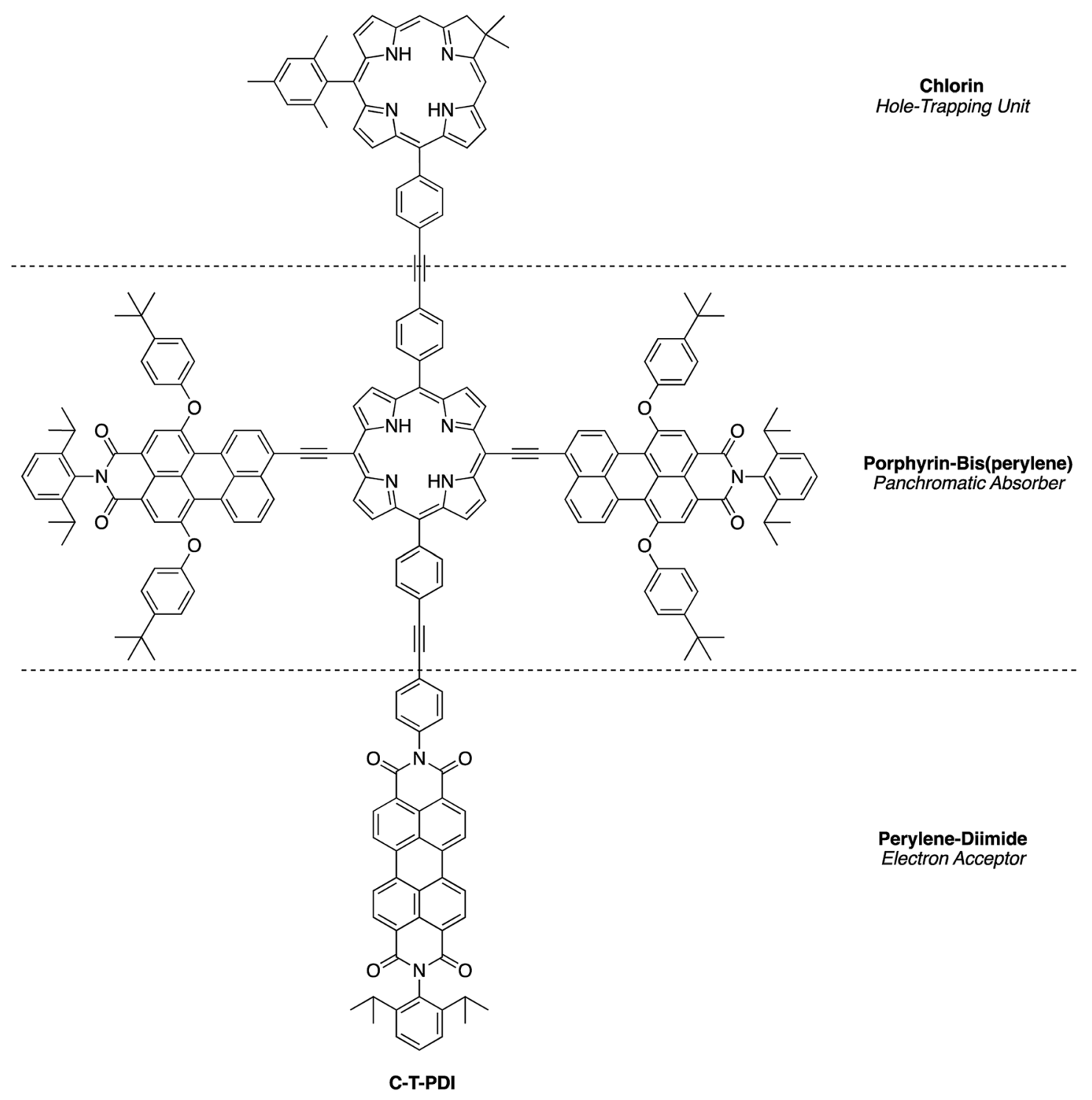

Chart 1 Target pentad array.

central bis(perylene-monoimide)porphyrin triad. The lower $\mathrm{S}_{1}$ energy of the central panchromatic porphyrin-based triad unit versus that of a standard chlorin is one of the functionally important features of the C-T-PDI pentad. Redox potentials of reported benchmark compounds with similar structures of the chlorin, panchromatic bis(perylene-monoimide)porphyrin triad, and the perylene-diimide constituents ${ }^{28,36-38}$ were considered in the design of an array to achieve photoinduced charge separation. The envisaged processes based on the choices are illustrated in Fig. 2: the central panchromatic triad (in both the ground and excited state) is more readily oxidized compared to the perylene-diimide and more readily reduced relative to the chlorin moiety, whereupon a charge-separated state is expected with the electron localized at the perylenediimide and the hole trapped at the chlorin.

One slight structural modification in the arrays reported here compared with the previously made triad $\mathbf{P M I}_{\mathbf{2 T}} \mathbf{P}$ is the $\mathrm{N}$ substituents of the imido groups in the perylenes. ${ }^{29,39}$ The prior 2,5-di-tert-butylphenyl substituents are replaced with 2,6-diisopropylphenyl groups, because the former substituents can give rise to atropisomers, ${ }^{\mathbf{4 0 - 4 2}}$ thereby complicating NMR analysis. The use of 2,6-diisopropyl versus 2,5-di-tert-butyl groups for solubilization has insignificant effects on perylene photophysics and energetics, ${ }^{\mathbf{4 3}}$ in large part due to the presence of a node at the perylene-imide nitrogen atom in both the HOMO and the lowest unoccupied molecular orbital (LUMO). ${ }^{\mathbf{1 1}}$

\section{Synthesis}

Eleven target compounds (Charts 2-4) were prepared for comparison with the pentad, including two free base tetrads (TPDI and C-T, omitting either the chlorin or the perylene-diimide moiety in the pentad) and a zinc chelate (ZnT-PDI); two free base triads (T-Ph and C-P-PDI) and their zinc chelates (ZnT-Ph and ZnC-ZnP-PDI); a monomeric perylene-diimide (PDI-Ph); a monomeric chlorin (C-Ph); and a monomeric porphyrin (PTMS/TIPS) bearing ethynes with trimethylsilyl and 


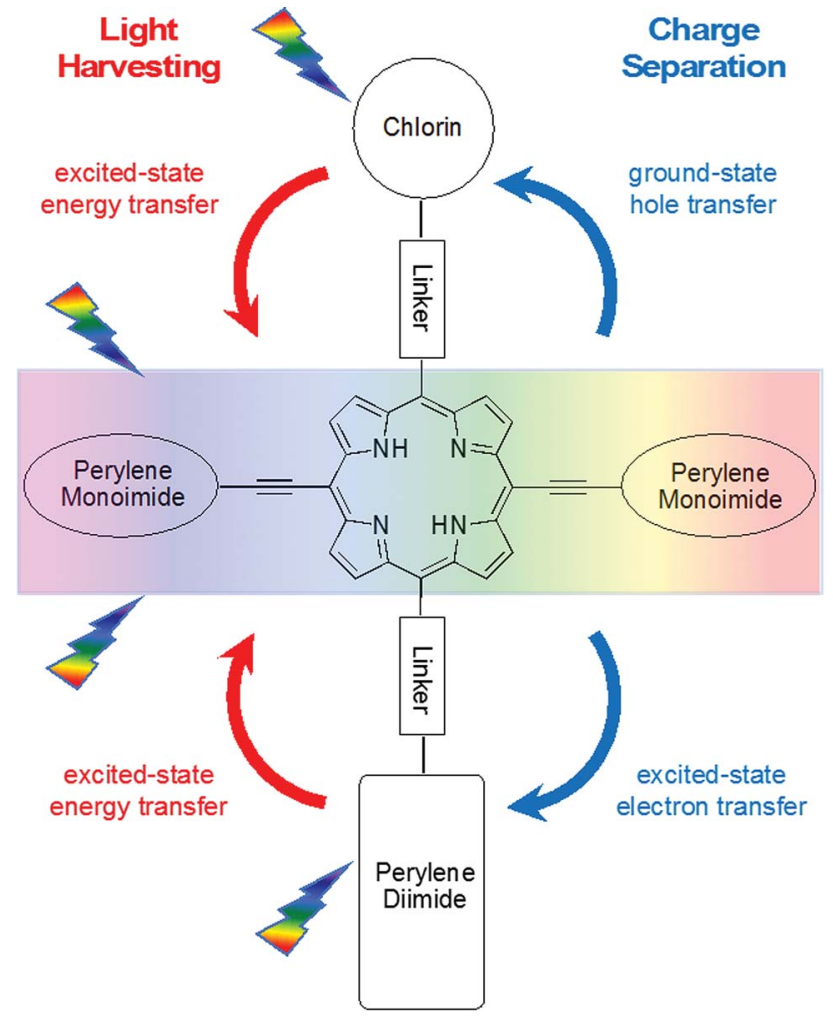

Fig. 2 Illustration of the expected light-harvesting and charge-separation processes in pentad C-T-PDI.

triisopropylsilyl protecting groups, and related zinc chelate (ZnP-H/TIPS). Zinc chelates were prepared to tune the electrochemical properties (because zinc chelates are more easily oxidized than the free base forms), providing more insights to the intramolecular electron-transfer processes in the arrays.

The pentad C-T-PDI contains four functional entities attached to the core porphyrin via ethynyl and ethynylphenyl linkers. The building blocks include a trans- $\mathrm{A}_{2} \mathrm{BC}$-porphyrin, ${ }^{44}$ which constitutes the core of the pentad and establishes a starshaped architecture; an iodophenyl-chlorin, ${ }^{35}$ an ethynyl-perylene-monoimide,,$^{45}$ and an iodophenyl-perylene-diimide..$^{37,42}$ The preparation of tetrapyrrole arrays with direct ethynyl linkages was first reported by Arnold ${ }^{46}$ next developed by Anderson $^{47}$ and Therien, ${ }^{48}$ and has since found widespread use. $^{18,26,49-53}$ The chief reaction for joining building blocks to construct either direct ethynyl linkers or longer diphenylethyne linkers entails Pd-mediated Sonogashira coupling of halo-(iodo or bromo) and ethynyl-substituted reactants. Such reactions with free base tetrapyrroles must be carried out in the absence of copper to avoid unwanted metalation..$^{54,55}$

Porphyrin building blocks. Two trans- $\mathrm{A}_{2} \mathrm{BC}$-porphyrins, 2$\mathbf{B r}_{2} / \mathbf{T M S}$ and 4-Br $\mathbf{B r}_{2} / \mathbf{T M S} / \mathbf{T I P S}$, provided building blocks for the benchmark tetrads (C-T and T-PDI) and the target pentad C-TPDI, respectively. The " $2+2$ " condensation ${ }^{56}$ of the diimino derivative of $\mathbf{1}^{57}$ and dipyrromethane 1-TMS ${ }^{57,58}$ generated the corresponding trans-AB zinc porphyrin Zn2-TMS in $40 \%$ yield. Subsequent demetalation ${ }^{43}(58 \%)$ and bromination ${ }^{59}$ with $N$ bromosuccinimide (NBS) of the two open meso positions (74\%) afforded the desired free base meso-dibromoporphyrin $2-\mathbf{B r}_{2} /$
TMS bearing a phenyl group and a TMS-protected ethynylphenyl group (Scheme 1).

Porphyrin building block 4-Br $/$ /TMS/TIPS (Scheme 2) bears two distinct ethynylphenyl units (with TMS and TIPS protecting groups for successive coupling reactions) and was synthesized in a strategy similar to that for porphyrin $\mathbf{2}-\mathbf{B r}_{2} / \mathbf{T M S}$. A dibutyltin-chelated diformyldipyrromethane $3,^{56}$ which was more readily purified than the free base counterpart, was synthesized according to the literature. The zinc trans-ABporphyrin Zn4-I/TMS, which bears one iodophenyl group and one TMS-protected ethynylphenyl group, was prepared therefrom with 1-TMS in 15\% yield. Sonogashira coupling of Zn4-I/ TMS and TIPS-acetylene in the presence of catalytic CuI ( $1 \mathrm{~mol} \%$ of the porphyrin) produced the zinc porphyrin Zn4-TMS/TIPS in $80 \%$ yield. Subsequent bromination ${ }^{59}$ and demetalation ${ }^{43}$ generated the free base dibromoporphyrin $\mathbf{4}-\mathbf{B r}_{2} / \mathbf{T M S} / \mathbf{T I P S}$ in a yield of $27 \%$ for two steps. The zinc-chelated benchmark compound ZnP-H/TIPS was also synthesized from the trans-ABporphyrin Zn4-TMS/TIPS in $44 \%$ yield, through three successive steps of bromination, coupling with phenylacetylene, and cleavage of the TMS group.

Chlorin building block and benchmark. The known iodophenyl-chlorin $5^{60}$ was employed as a building block for integration into the pentad. Pd-mediated coupling of the zinc chlorin counterpart $\mathbf{Z n} 5^{60}$ with phenylacetylene in tetrahydrofuran (THF) containing triethylamine (TEA) followed by demetalation with trifluoroacetic acid afforded the chlorin benchmark C-Ph in $84 \%$ yield (Scheme 3 ).

Perylene building blocks. The iodophenyl-perylene-diimide 7 was prepared by statistical imidation of the perylenebis(anhydride) 6 with two anilines-2,6-diisopropylaniline (3.0 equiv.) and 4 -iodoaniline (2.0 equiv.) - in 30\% yield (Scheme 4 ), following a reported method. ${ }^{37}$ The difference in the loading equivalents of two anilines is due to their unequal reactivity. Surprisingly, the reported synthesis of the unsymmetric perylene-diimide by partial hydrolysis of a symmetric perylenediimide precursor ${ }^{37,42}$ failed in our hands to generate the desired product 7. The perylene-diimide benchmark PDI-Ph was prepared thereafter by coupling with phenylacetylene in $52 \%$ yield. Synthesis of the perylene-monoimide building block 8 was previously reported. ${ }^{34}$

Construction of the benchmark triads and tetrads. With the five building blocks in hand (porphyrin $\mathbf{2}-\mathbf{B r}_{2} / \mathbf{T M S}$ and $\mathbf{4}-\mathbf{B r}_{2} /$ TMS/TIPS, chlorin 5, perylene-diimide 7 , and perylenemonoimide 8), the target arrays and benchmark compounds (Charts 2 and 3) were prepared through a series of Pd-mediated coupling reactions. Syntheses of triads T-Ph and ZnT-Ph, tetrads T-PDI, ZnT-PDI, and C-T all started from the shared porphyrin building block $2-\mathbf{B r}_{2} / \mathbf{T M S}$. Stepwise coupling with perylenemonoimide 8 followed by chlorin 5 (for C-T) or perylenediimide 7 (for T-PDI) afforded the free base arrays (Scheme 5).

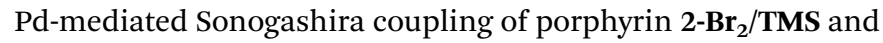
perylene-diimide 8 produced the triad T-Ph in $86 \%$ yield. Metalation of T-Ph with zinc acetate gave the zinc-chelated triad ZnT-Ph in $45 \%$ yield. The TMS-protecting group in T-Ph was removed by treatment with $\mathrm{K}_{2} \mathrm{CO}_{3}$ in a mixture of toluene/ $\mathrm{CH}_{3} \mathrm{OH}$, affording the ethynylphenyl triad $\mathbf{T}-\mathbf{P h}-\mathbf{H}$ 


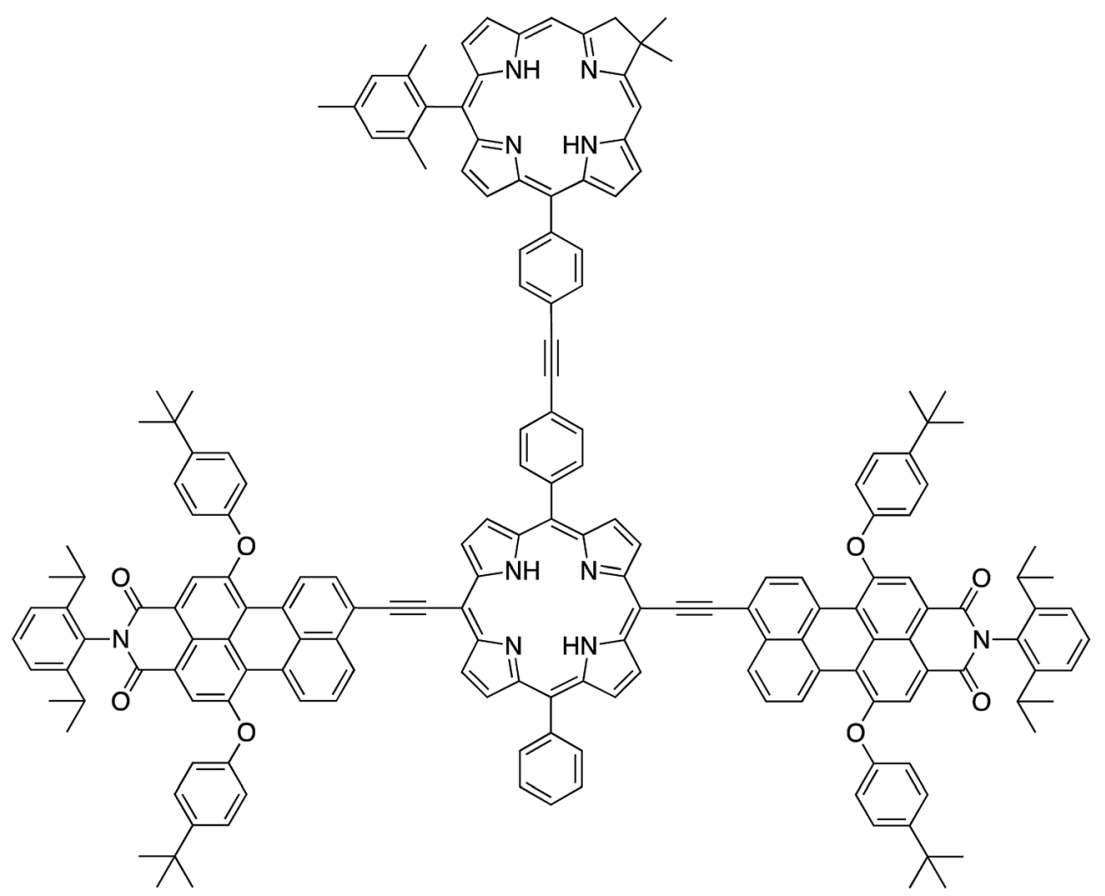

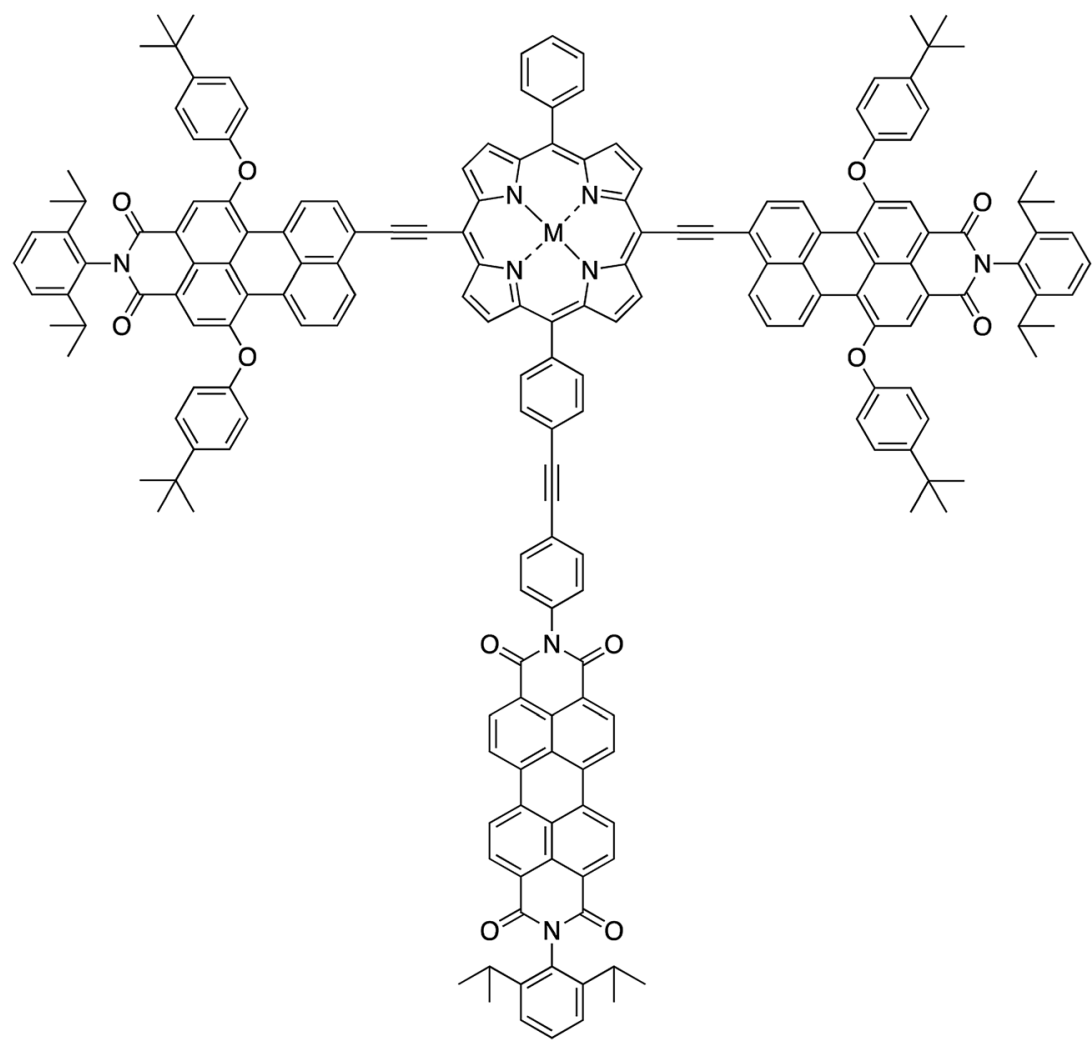

Chart 2 Constituent tetrad benchmarks.

quantitatively. Thereupon, T-Ph-H was coupled in the presence of $\mathrm{Pd}_{2}(\mathrm{dba})_{3} / \mathrm{P}(o \text {-tol })_{3}$ either with iodophenyl-chlorin 5 or iodophenyl-perylene-diimide 7 to generate the tetrad C-T or TPDI in $24 \%$ or $40 \%$ yield, respectively. Metalation of T-PDI with zinc acetate afforded the zinc tetrad ZnT-PDI.
Syntheses of the target pentad and chlorin-porphyrinperylene-diimide triads. The target pentad C-T-PDI and the chlorin-porphyrin-perylene-diimide triads (C-P-PDI and ZnCZnP-PDI) were also prepared through stepwise coupling reactions with the same building block porphyrin $4-\mathbf{B r}_{2} / \mathbf{T M S} / \mathbf{T I P S}$. The distinct protection of the ethyne units with trimethylsilyl 

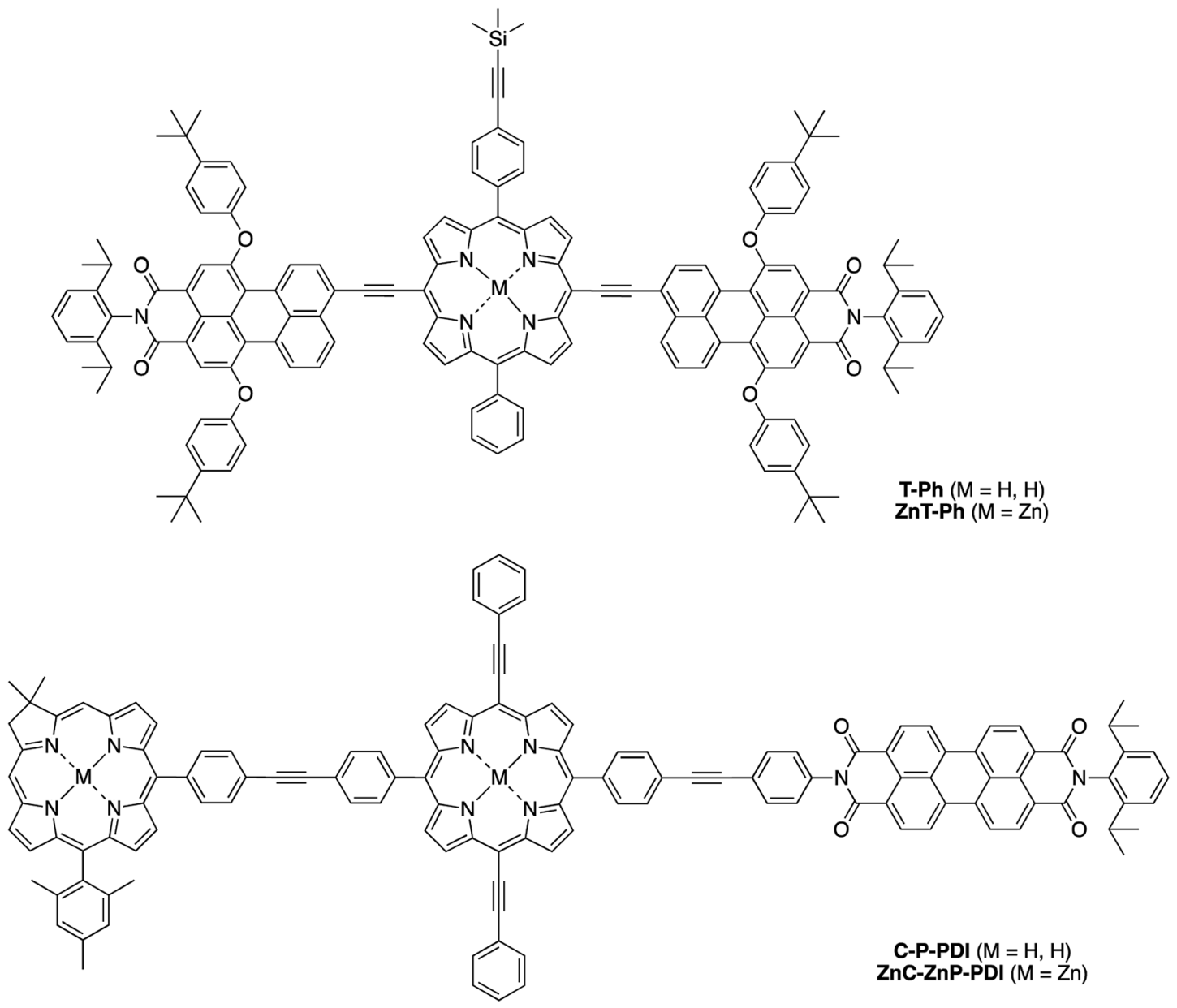

Chart 3 Constituent triad benchmarks.

and triisopropylsilyl groups afforded the opportunity for selective reactions.

Phenylethynyl groups were installed at the meso-positions of 4$\mathbf{B r}_{2} /$ TMS/TIPS through a Sonogashira reaction to afford the porphyrin benchmark P-TMS/TIPS in 78\% yield (Scheme 6). The TMS group in P-TMS/TIPS was thereafter removed with $\mathrm{K}_{2} \mathrm{CO}_{3}$ at room temperature, whereupon coupling of the resulting porphyrin and perylene-diimide 7 afforded the porphyrin-perylene-diimide<smiles>CCc1cccc(C(C)(C)C)c1N1C(=O)c2ccc3c4ccc5c6c(ccc(c7ccc(c2c37)C1=O)c64)C(=O)N(c1ccc(C#Cc2ccccc2)cc1)C5=O</smiles><smiles></smiles>

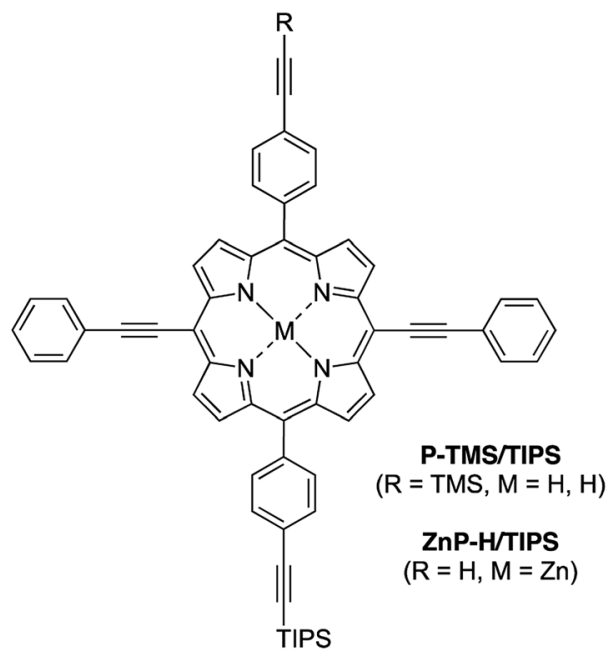

Chart 4 Constituent monomer benchmarks. 

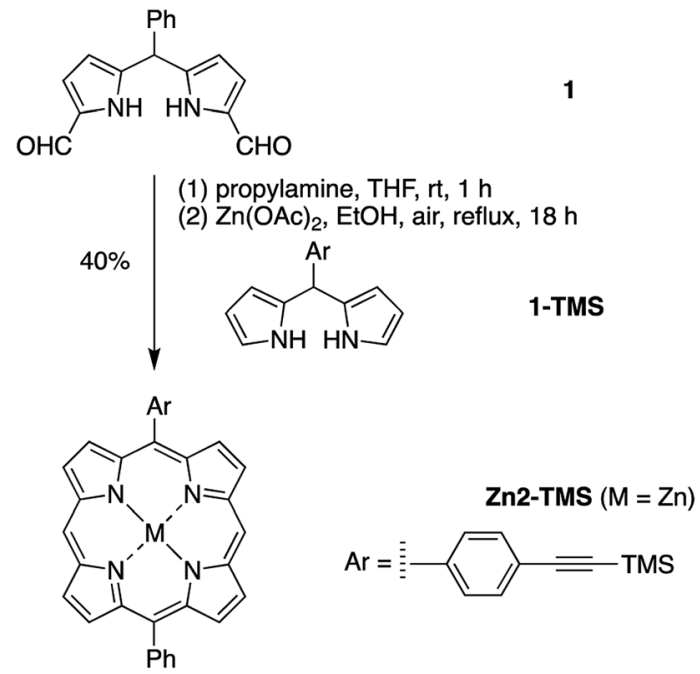

$58 \% \downarrow \mathrm{CF}_{3} \mathrm{CO}_{2} \mathrm{H}, \mathrm{CH}_{2} \mathrm{Cl}_{2}, \mathrm{rt}, 30 \mathrm{~min}$

2-TMS $(M=H, H)$

$74 \% \downarrow$ NBS, pyridine, $\mathrm{CH}_{2} \mathrm{Cl}_{2}, 0^{\circ} \mathrm{C}, 1 \mathrm{~h}$

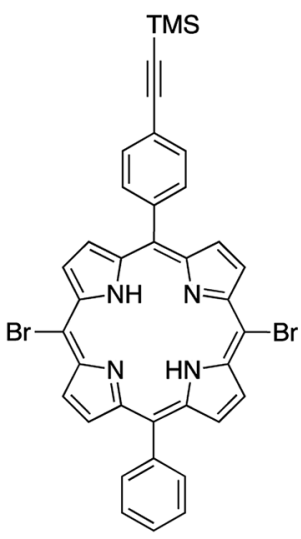

2-Br $2 / T M S$

Scheme 1 "2 +2 " condensation to prepare porphyrin building block 2- $\mathrm{Br}_{2} / \mathrm{TMS}$.

dyad 9 (49\% yield). Dyad 9 has limited solubility in many organic solvents (toluene, $\mathrm{CH}_{2} \mathrm{Cl}_{2}$, chloroform, THF, acetonitrile, methanol, or DMSO), but the solubility could be improved upon zinc chelation (not shown). Despite the meager solubility, dyad 9 in a saturated solution $(\sim 1 \mathrm{mM})$ was deprotected with tetrabutylammonium fluoride (TBAF) and then coupled with the chlorin building block 5 in the presence of $\operatorname{Pd}_{2}(\mathrm{dba})_{3} / \mathrm{P}(o \text {-tol })_{3}$ to produce the chlorin-porphyrin-perylene-diimide triad C-P-PDI. Subsequent zinc chelation generated the triad ZnC-ZnP-PDI, wherein both the porphyrin and the chlorin macrocycles are zinc chelated.

The pentad C-T-PDI was synthesized similarly through the stepwise incorporation of various building blocks (Scheme 7). Perylene-monoimide 8, instead of phenylethynyl groups in the case of C-P-PDI, was installed on the meso-positions of the porphyrin 4-Br $\mathbf{B r}_{2} / \mathbf{T M S} / \mathbf{T I P S}$, generating the panchromatic triad $\mathbf{T}$ TMS/TIPS. A succession of reactions - deprotecting with $\mathrm{K}_{2} \mathrm{CO}_{3}$, coupling with perylene-diimide 7 , and again deprotecting with TBAF - afforded the tetrad T-H/PDI in $12 \%$ overall yield for the three steps. The final coupling entailed reaction of the tetrad with
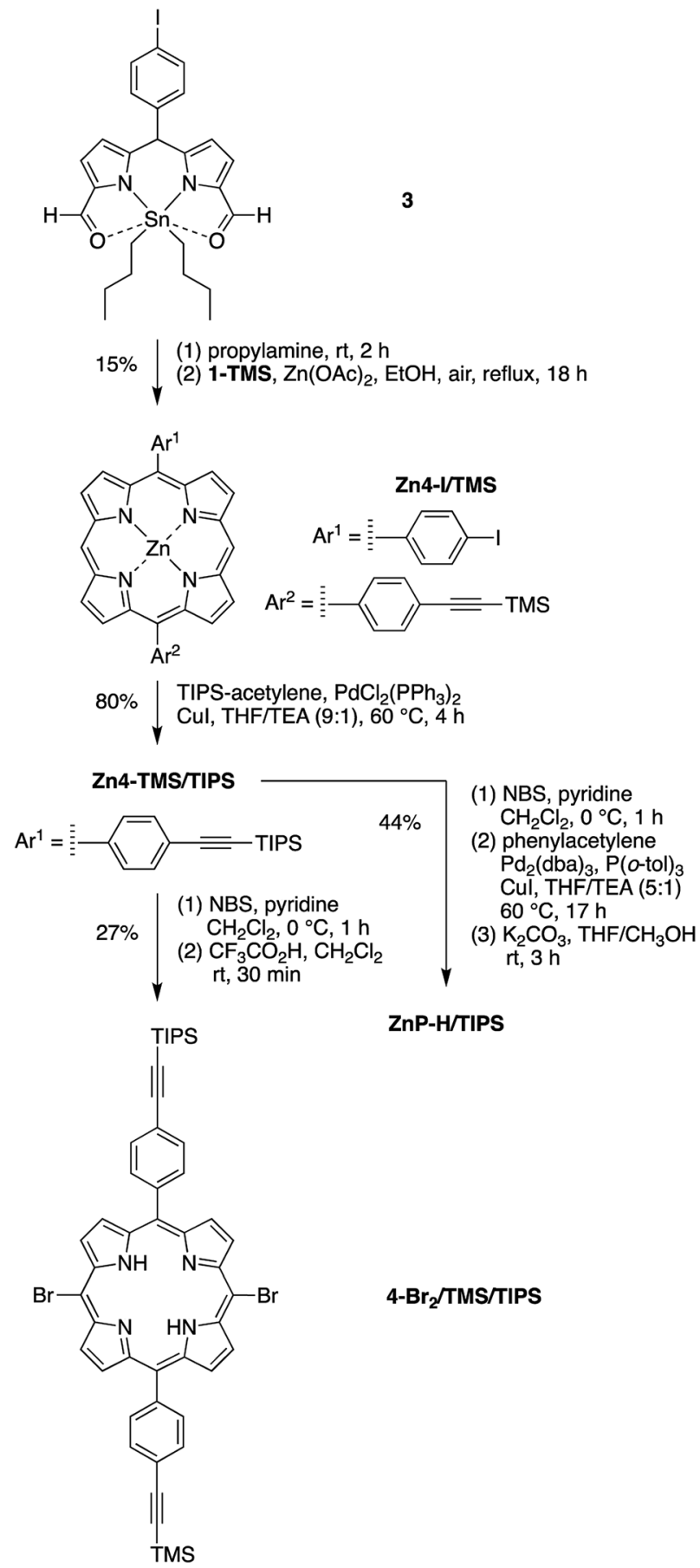

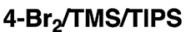

Scheme 2 Preparation of the porphyrin building block $4-\mathrm{Br}_{2} / \mathrm{TMS} /$ TIPS and benchmark ZnP-H/TIPS

iodophenyl-chlorin 5 to complete the synthesis of the target pentad C-T-PDI in $27 \%$ yield. The pentad-forming reaction was monitored with analytical size exclusion chromatography (SEC), as has been done previously with multiporphyrin arrays (see ESI $\dagger$ ). ${ }^{31,32}$ The pentad array and all benchmarks were also characterized by analytical SEC and MALDI-MS prior to any photophysical studies. On the basis of the analytical SEC traces, the purity of each array was estimated to be $>99 \%$, which is suitable for further photophysical characterization. 


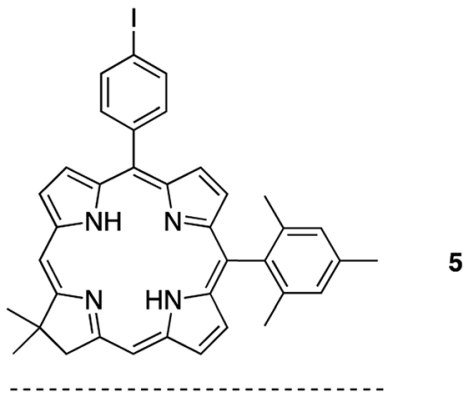

5
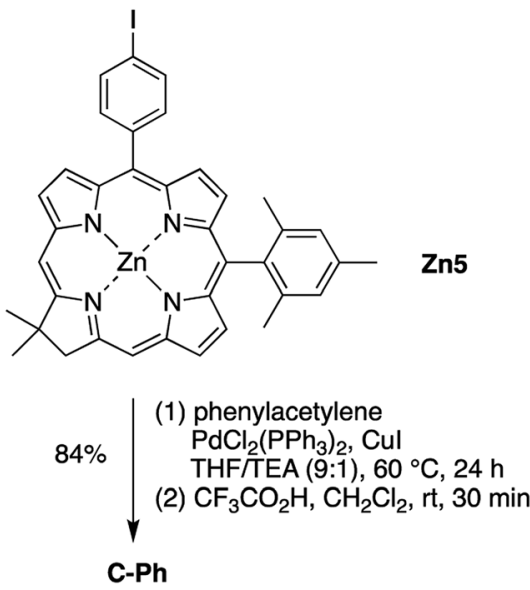

Scheme 3 The chlorin building block 5 and the preparation of benchmark compound C-Ph.

\section{Photophysical studies}

Absorption spectra. Steady-state absorption spectra of the pentad C-T-PDI and all benchmark arrays were measured (in toluene at room temperature) as a first step toward understanding intramolecular photophysical processes. Spectra for the pentad and constituent tetrads and triads containing a panchromatic bis(perylene-monoimide)porphyrin unit (denoted T), along with relevant monomers, are shown in Fig. 3 (solid). Spectra for related reference arrays in which the bis(perylene-monoimide)porphyrin core is replaced by a simple porphyrin, along with associated monomers, are shown in Fig. 4 (solid). The absorption spectral properties are summarized in Table 1 . Consistent with the previously reported panchromatic triads, ${ }^{29,39}$ the triad T-Ph shows a broad distribution of absorption from the near-UV to near-IR region. Compared to the spectrum of a typical porphyrin (see that for P-TMS/TIPS in Fig. 4C), the spectral distribution for $\mathbf{T}-\mathbf{P h}$ (average $\varepsilon \sim$ $80000 \mathrm{M}^{-1} \mathrm{~cm}^{-1}$ ) reflects a substantial shift of absorption strength from the typically intense porphyrin near-UV Soret feature(s) (typical peak $\varepsilon$ of $350000-400000 \mathrm{M}^{-1} \mathrm{~cm}^{-1}$ ) into the typically weak visible transitions (typical peak $\varepsilon$ of $10000-$ $20000 \mathrm{M}^{-1} \mathrm{~cm}^{-1}$ ), accompanied by a bathochromic shift of features such as the $S_{0} \rightarrow S_{1}$ band along with the possible generation of new bands (e.g. at $\sim 650 \mathrm{~nm}$ ). Corresponding differences can be seen for the corresponding zinc chelatespanchromatic triad ZnT-Ph (Fig. 3F) compared to porphyrin ZnP-H/TIPS (Fig. 4D). The substantial shift of intensity from the porphyrin near-UV Soret region into and across the visibleregion features upon attachment of perylene-monoimides via
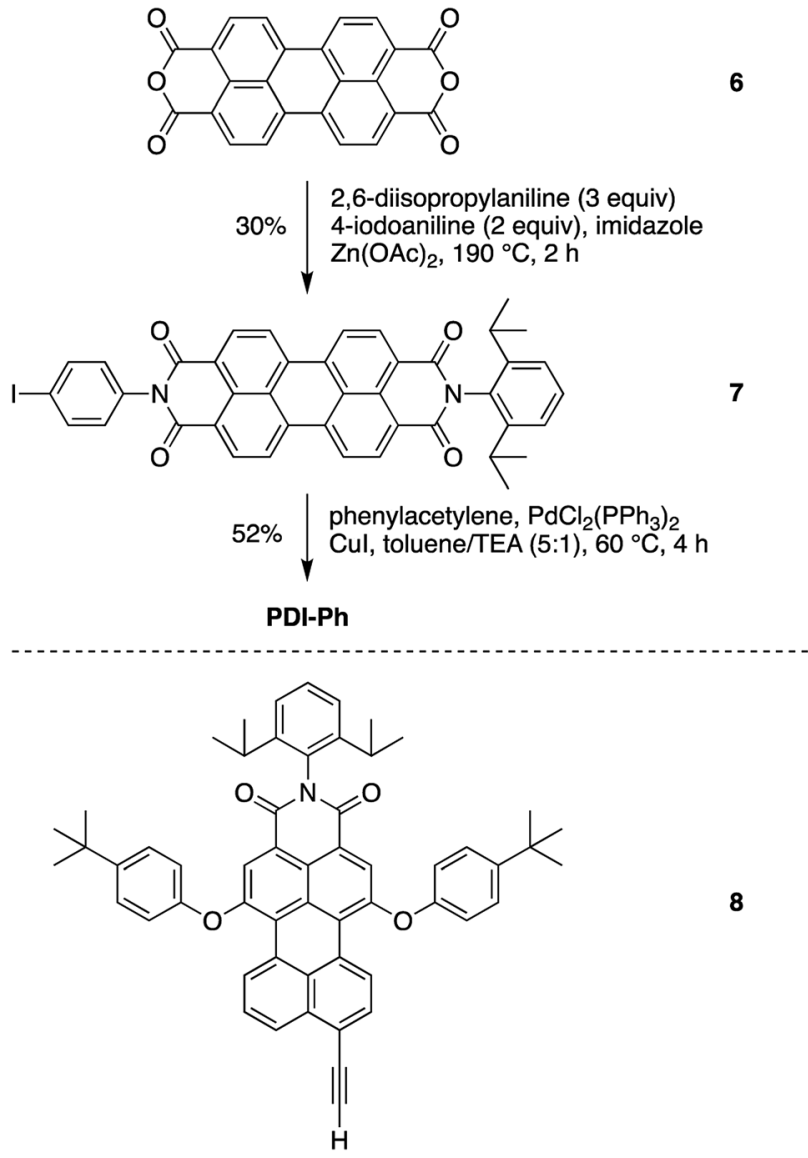

Scheme 4 Synthesis of the perylene-diimide building block 7, and the benchmark PDI-Ph.

direct ethyne linkers arises at least in part from a significant diminution in mixing of the key porphyrin one-electron excitedstate configurations within the four-orbital model. ${ }^{28,30}$ Such a diminution in configuration interaction reduces the constructive configurational interference that affords the normal intense near-UV bands and the destructive interference that gives the typically weak visible bands within the Gouterman four-orbital model. ${ }^{61-63}$ A decrease in configuration interaction is further accentuated by the shifts in energies of the frontier molecular-orbital, which also contributes to the bathochromic shift in the $S_{0} \rightarrow S_{1}$ transition.

As expected, the absorption spectra of the pentad (C-T-PDI) and two tetrads (C-T and T-PDI) show panchromatic features similar to those of triad T-Ph (Fig. 3, panels A-C and E). In analogy, the spectrum of the tetrad containing a zinc porphyrin (ZnT-PDI) has similar panchromaticity as reference triad ZnTPh (Fig. 3, panels D and F). The spectra of the tetrads generally reflect the contributions of the corresponding triad (T-Ph or ZnT-Ph) and monomer (C-Ph or PDI-Ph), with some modest changes in relative intensities and peak positions. In turn, the spectrum of pentad C-T-PDI has features that correspond to those in the spectra of tetrad C-T and monomer PDI-Ph, or tetrad T-PDI and monomer C-Ph, again with some shifts in intensities and wavelengths. For example a slight bathochromic shift in the Soret band of the chlorin moiety (at $418 \mathrm{~nm}$ ) is 

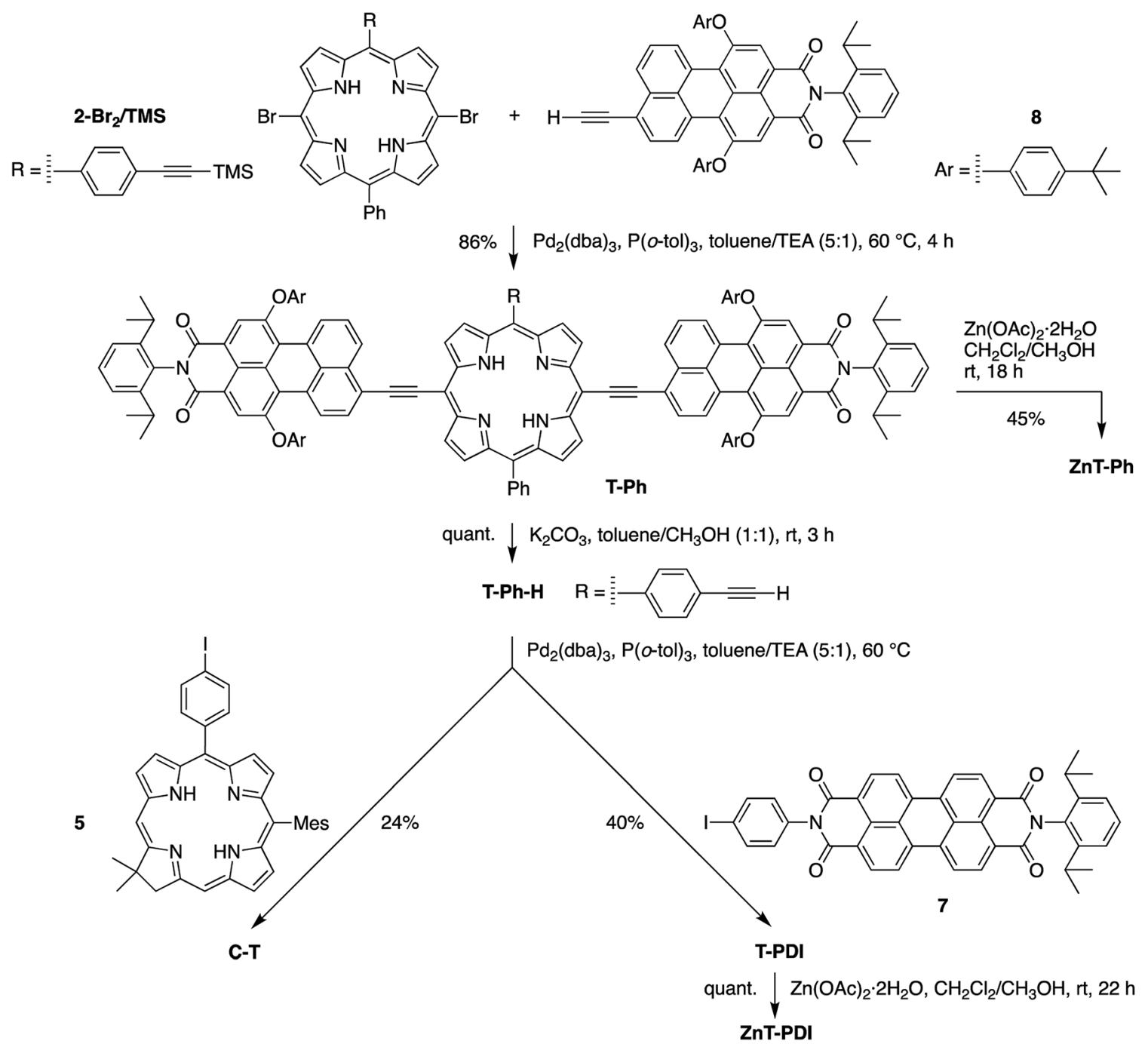

Scheme 5 Preparation of triads (T-Ph, ZnT-Ph) and tetrads (C-T, T-PDI, ZnT-PDI).

observed in the pentad compared to the tetrad C-T $(2 \mathrm{~nm})$ and chlorin benchmark C-Ph $(4 \mathrm{~nm})$. Broadening of this band is also observed for the pentad [full width at half maximum $(\mathrm{FWHM})=$ $65 \mathrm{~nm}]$ compared to the tetrad C-T $(40 \mathrm{~nm})$ and the monomer CPh $(33 \mathrm{~nm})$.

The band at $\sim 530 \mathrm{~nm}$ due to perylene-diimide absorption is essentially superimposable on that of the tetrad T-PDI and the monomeric PDI-Ph, except for a $6 \mathrm{~nm}$ hypsochromic shift for the former relative to the latter. For pentad C-T-PDI, the $\mathrm{S}_{0} \rightarrow \mathrm{S}_{1}$ feature at $\sim 741 \mathrm{~nm}$ due to the absorption of the panchromatic bis(perylene-monoimide)porphyrin moiety shows a bathochromic shift and broadening $(\mathrm{FWHM}=54 \mathrm{~nm})$ compared with that of tetrad C-T $(727 \mathrm{~nm}$, FWHM $=46 \mathrm{~nm})$, tetrad T-PDI $(728 \mathrm{~nm}, \mathrm{FWHM}=71 \mathrm{~nm})$, and triad T-Ph $(725 \mathrm{~nm}, \mathrm{FWHM}=46$ $\mathrm{nm})$. This effect on the $\mathrm{S}_{0} \rightarrow \mathrm{S}_{1}$ energy and also in the relative intensity of the absorption band is likely due in part to substituent effects on the electronic properties of the central triad. In particular, T-Ph contains one phenyl ring and one ethynylphenyl group at the two meso-positions apart from the meso-positions that bear ethynyl linkers to the perylenemonoimides (Chart 3). In each tetrad the ethynylphenyl group is converted to a diphenylethyne linker to the chlorin or perylene-diimide (Chart 2). The pentad has two such diphenylethyne groups, terminated with the chlorin or perylene-diimide (Chart 1). Thus, in progressing from the triad to pentad, the change in terminal moieties on the ethynylphenyl and phenyl groups propagates to the porphyrin and sufficiently alters the porphyrin molecular orbital energies and configuration interaction to affect the characteristics of the $S_{0} \rightarrow S_{1}$ transition.

Despite the above-noted differences in certain spectral characteristics, the generally similar spectral features of the pentad and the corresponding constituents indicate that ground-state electronic interaction between the panchromatic core and either the perylene-diimide or the chlorin (via a diphenylethyne linker) are relatively weak, but not zero. Thus, addition of the chlorin and perylene-diimide moieties does not impart a substantial electronic perturbation to the central triad. In contrast, replacing the perylene-monoimide-ethynyl units attached to the central porphyrin with phenylethynyl groups restores the strong Soret bands and effectively diminishes panchromaticity, affording the spectrum of the triad C-P-PDI as a linear combination of those from the three monomeric 


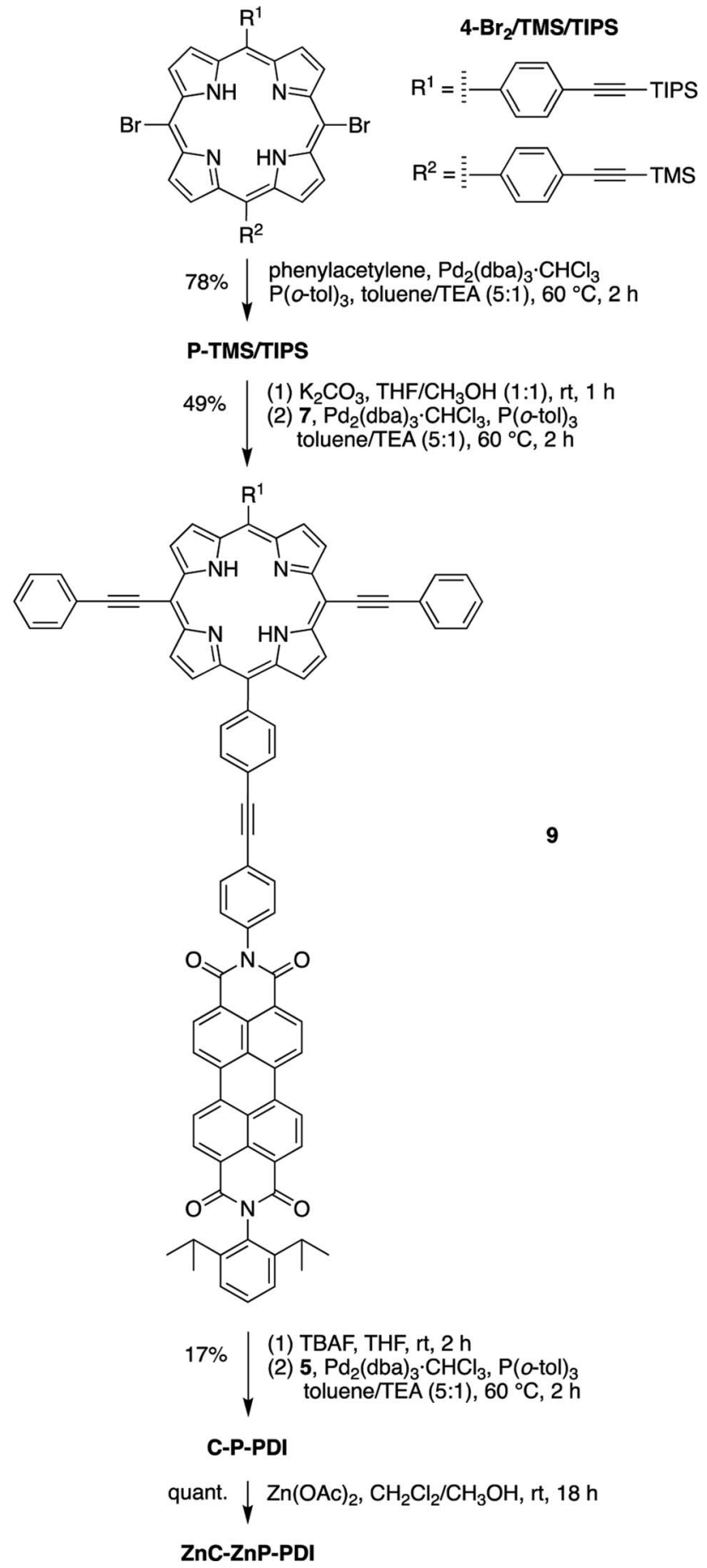

Scheme 6 Synthesis of triads C-P-PDI and ZnC-ZnP-PDI from porphyrin 4- $\mathrm{Br}_{2}$ /TMS/TIPS.

components (Fig. 4, panels A, C, E and F). The same is true for the triad containing a central zinc porphyrin (ZnC-ZnP-PDI) relative to its three components (Fig. 4, panels B, D-F).

Fluorescence spectra. The fluorescence emission spectra of the pentad and all benchmark arrays measured in toluene at room temperature are also shown in Fig. 3 and 4 (dashed lines). The emission spectral properties including the (Stokes) shift between the $S_{0} \rightarrow S_{1}$ absorption and $S_{1} \rightarrow S_{0}$ emission maxima are listed in Table 1 . The emission pattern of the panchromatic arrays (tetrad $\mathbf{C}-\mathbf{T}$ and T-PDI, and the triad $\mathbf{T}-\mathbf{P h}$ ) is porphyrinlike, albeit at much lower energy than a typical monomeric porphyrin, or even P-TMS/TIPS for which the meso-substituents (two phenylethynyl groups, an ethynylphenyl and a phenyl ring) cause a significant bathochromic shift compared to a porphyrin lacking ethyne-containing substituents. As reported previously, ${ }^{28,30}$ arrays that contain strongly electronically coupled porphyrin-perylene-monoimide units exhibit a chromophoreinduced reduction in configuration interaction involving the four frontier molecular orbitals of the central porphyrin, which results in a redistribution of intensity among the bands in the absorption spectra. This effect accounts at least in part for the non-mirror-image relationship observed for the absorption and the fluorescence of the porphyrin-bis(perylene-monoimide)containing architectures. A change in nuclear coordinates of the array and the solvent may also contribute to diminished mirror symmetry, and also to a somewhat larger Stokes shift for such architectures compared to a typical porphyrin. ${ }^{30}$

There is a resemblance of the fluorescence spectra of the two tetrads (C-T and T-PDI) and that of the triad T-Ph, as well as a similar resemblance between the emission of the zinc-chelate tetrad ZnT-PDI and reference monomer (Fig. 3, panels D and F). Fluorescence emission of the pentad and tetrads are predominantly from the central panchromatic bis(perylenemonoimide)-porphyrin unit, regardless of excitation wavelength. This is shown in Fig. 4A for pentad C-T-PDI, for excitation wavelengths that should primarily excite the chlorin or perylenes. This finding is consistent with efficient energy transfer from either the chlorin (in C-T) or the perylene-diimide (in T-PDI) to the central bis(perylene-monoimide)porphyrin.

As noted above, prior work on arrays that contain one (or more) perylene-monoimide unit(s) coupled via an ethyne to a porphyrin are best treated as a supermolecule: excitation within any absorption band, including features in the green region that one would normally associate with the perylene, results in rapid internal conversion within the array to produce the tetrapyrrole-like $S_{1}$ excited state, from which fluorescence occurs. Thus, it is expected that rapid energy transfer from the excited chlorin or excited perylene-diimide to the bis(perylenemonoimide)porphyrin unit in the pentad and tetrads will give rise to tetrapyrrole-like emission from the $S_{1}$ excited state of that triad unit. This is observed for the pentad and tetrads, even if the (Förster) spectral overlap of the emission from the excited perylene-diimide unit (e.g., in C-T-PDI and T-PDI) would be the greatest with the green-region absorption of nominal perylenemonoimides of the central panchromatic bis(perylenemonoimide)porphyrin triad. Thus, observations here support the view that the arrays containing a bis(perylene-monoimide) porphyrin unit are efficient in absorbing light spanning the near-UV and into the near-IR and producing a discrete tetrapyrrole-like $S_{1}$ state from which charge separation can ensue.

In comparison with the aforementioned arrays, the fluorescence of the non-panchromatic triad C-P-PDI is at a higher energy, because no strongly coupled perylene-monoimide pigments are integrated at the central porphyrin. However, the presence of the two meso-phenylethynyl groups on the 
<smiles>[R]C#Cc1ccc(C#CC(C)(C)C)cc1</smiles>

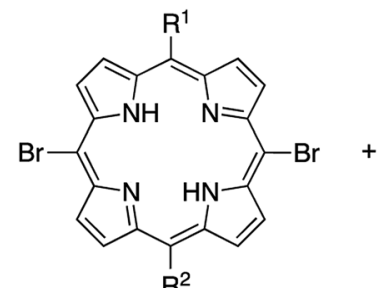<smiles></smiles><smiles>CC(C)(C)c1ccc(I)cc1</smiles>

$76 \% \downarrow \mathrm{Pd}_{2}(\mathrm{dba})_{3}, \mathrm{P}(\mathrm{o} \text {-tol })_{3}$, toluene/TEA $(5: 1), 60^{\circ} \mathrm{C}, 4 \mathrm{~h}$

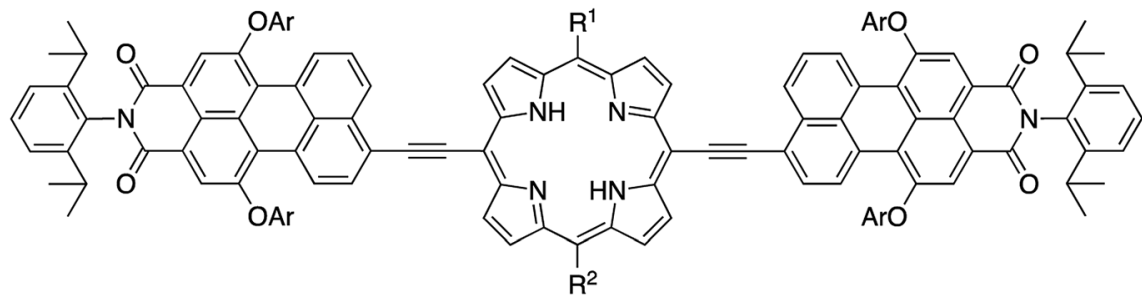

T-TMS/TIPS

(1) $\mathrm{K}_{2} \mathrm{CO}_{3}, \mathrm{THF} / \mathrm{CH}_{3} \mathrm{OH}$, rt, $1 \mathrm{~h}$

(2) $7, \mathrm{Pd}_{2}(\mathrm{dba})_{3}, \mathrm{P}(\mathrm{o} \text {-tol })_{3}$, toluene/TEA $(5: 1), 60^{\circ} \mathrm{C}, 4 \mathrm{~h}$ (3) TBAF, THF, it, $1 \mathrm{~h}$

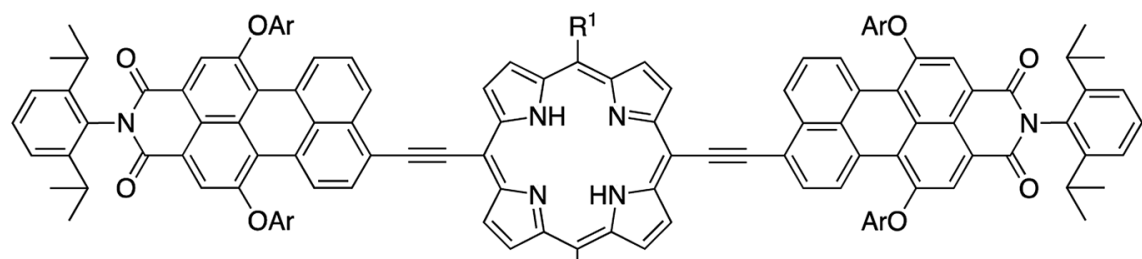

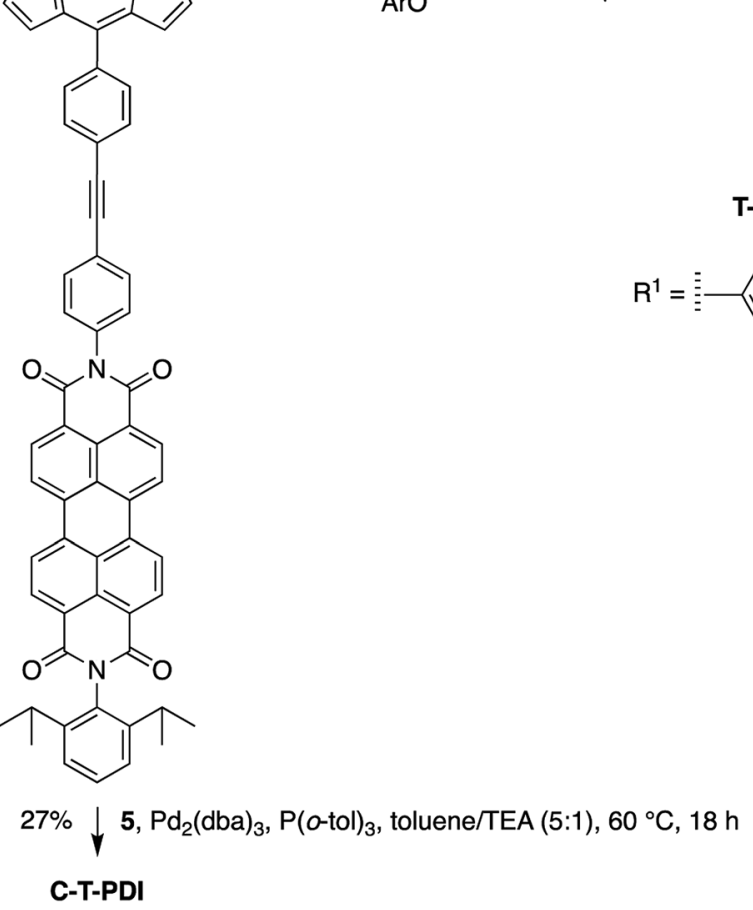

T-H/PDI<smiles>C#Cc1ccc([V]=[Tl])cc1</smiles>

Scheme 7 Synthesis of the target pentad C-T-PDI

central porphyrin causes sufficient bathochromic shifts in the $\mathrm{S}_{0} \rightarrow \mathrm{S}_{1}$ absorption and corresponding $\mathrm{S}_{1} \rightarrow \mathrm{S}_{0}$ fluorescence bands that the $S_{1}$ excited state remains at a lower energy than the $S_{1}$ of the chlorin and the perylene-diimide pigments (Fig. 4). The same is true for triad ZnC-ZnP-PDI, in which the central bis(phenylethynyl)porphyrin is a zinc chelate, which tends to hypsochromically shift the $S_{0} \leftrightarrow S_{1}$ transitions compared to those of the free base analogue (Fig. 4F). Thus, the observation again of porphyrin fluorescence independent of excitation wavelength indicates that these triads afford efficient energy transfer from the two terminal chromophores to the central porphyrin, from which charge separation can occur.

Fluorescence quantum yields. The fluorescence quantum yields $\left(\Phi_{\mathrm{f}}\right)$ for all the arrays prepared herein along with those for 


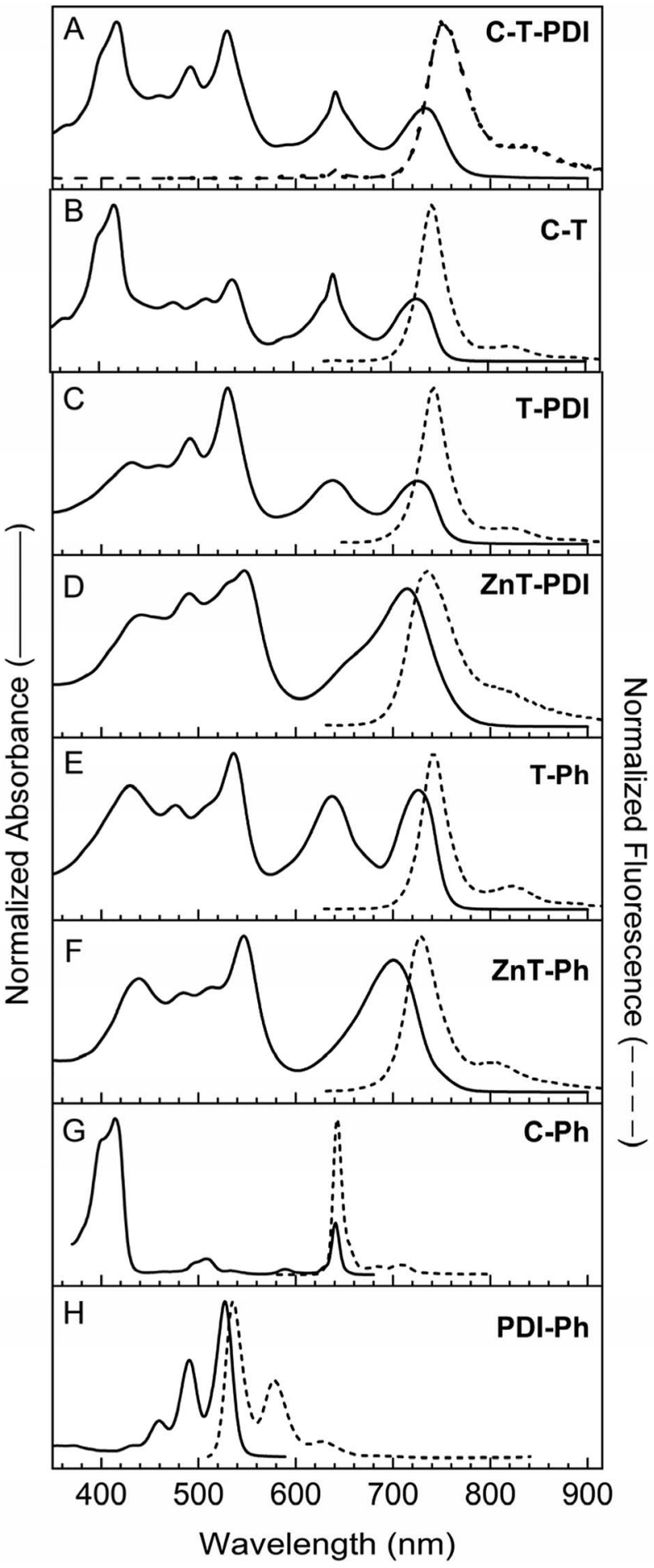

Fig. 3 The absorption (solid) and fluorescence (dashed) spectra of pentad (A) containing a central panchromatic bis(perylene-monoimide)porphyrin triad (denoted $T$ ) and benchmark tetrads $(B-D)$, triads ( $E$ and $F$ ) and monomers ( $G$ and $H)$. In (A), fluorescence spectra for the pentad were obtained using primarily excitation of a nominal absorption band of the chlorin or perylenes, with essentially the same result.

relevant benchmarks are given in the last column of Table 1. Starting with the panchromatic arrays, pentad C-T-PDI and tetrads C-T, T-PDI, and ZnT-PDI show no apparent dependence

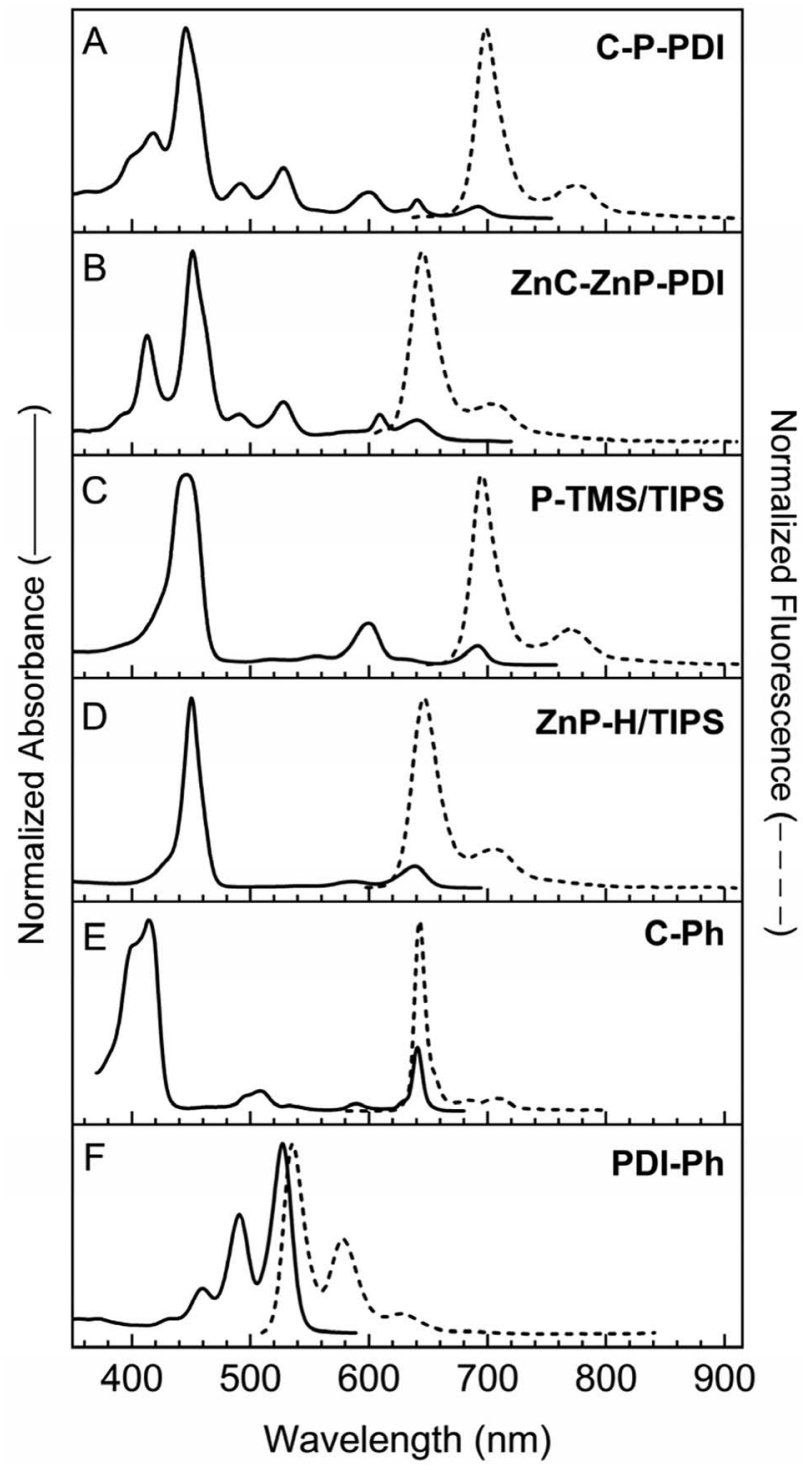

Fig. 4 The absorption (solid) and fluorescence (dashed) spectra of triads (A and B) containing a central porphyrin (denoted $\mathrm{P}$ ) and benchmark monomers $(\mathrm{C}-\mathrm{F})$.

of the $\Phi_{\mathrm{f}}$ value on excitation wavelength. The same is true of benchmark triads T-Ph and ZnT-Ph. As can be inferred from the fluorescence spectra described in the prior section, these $\Phi_{\mathrm{f}}$ values reflect emission from the excited bis(perylenemonoimide)porphyrin triad unit $\left(\mathrm{T}^{*}\right)$ in these arrays.

The $\Phi_{\mathrm{f}}$ of C-T $(0.26)$ and T-PDI $(0.23)$ are reduced from that for the benchmark panchromatic triad $(0.30)$ by $13 \%$ and $23 \%$, respectively, indicating modest yields of excited-state electron transfer. On the basis of the redox properties, the most likely product of hole/electron transfer would be $\mathrm{C}^{+}-\mathrm{T}^{-}$and $\mathrm{T}^{+}-\mathrm{PDI}^{-}$in the two tetrads, respectively. The $\Phi_{\mathrm{f}}$ for pentad C-T-PDI $(0.16)$ is reduced by $47 \%$ from the panchromatic triad benchmark, suggesting that the yield of hole/electron-transfer initiated in the excited triad $\left(\mathrm{T}^{*}\right)$ in this case is roughly the sum of the yields in the two tetrads. These measurements do not identify the product or product ratio, but the results tend to suggest that both $\mathrm{C}^{+}-\mathrm{T}^{-}$PDI and $\mathrm{C}^{-} \mathrm{T}^{+}-\mathrm{PDI}^{-}$form in the pentad. A subsequent ground- 


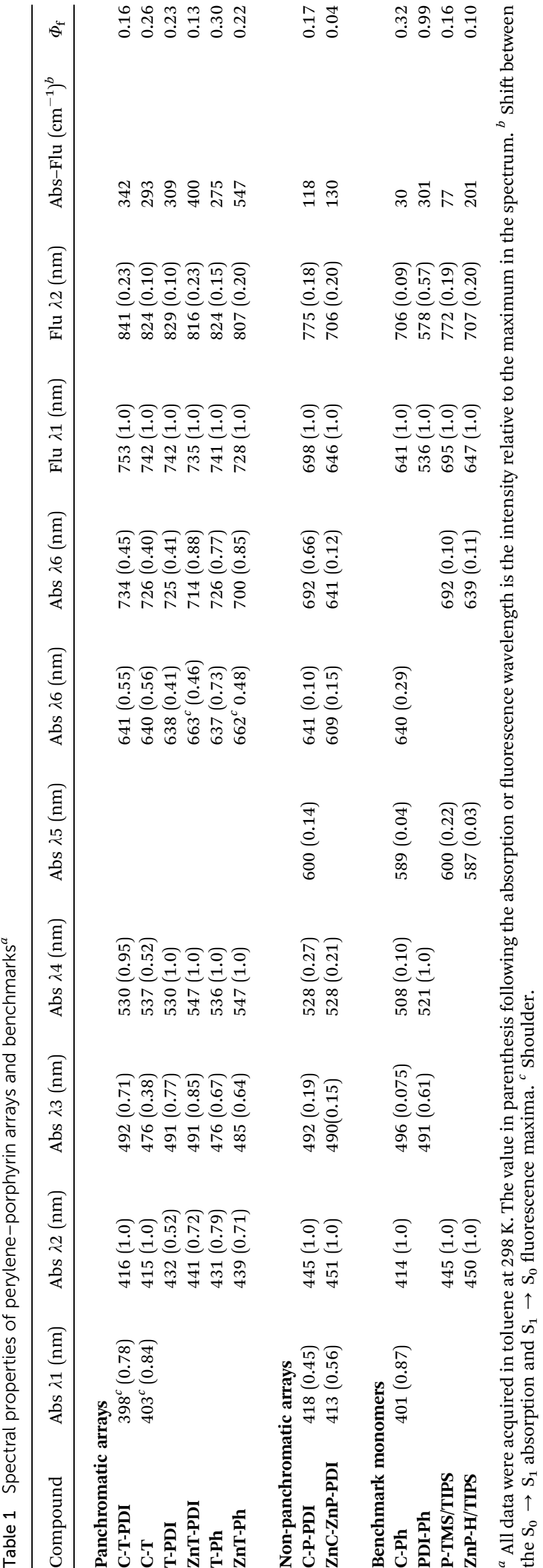

state hole/electron step would be needed for each intermediate to produce the full charge-separated state $\mathrm{C}^{+}-\mathrm{T}-\mathrm{PDI}^{-}$.

Tetrad ZnT-PDI and benchmark panchromatic triad ZnT-Ph were prepared to test whether the more facile oxidization of a zinc chelate versus the free base form would enhance excitedstate electron transfer in these types of systems. The $\Phi_{\mathrm{f}}$ of ZnTPDI $(0.13)$ is reduced by $41 \%$ compared to benchmark panchromatic triad ZnT-Ph (0.22), indicating that the electrontransfer yield (to produce $\mathrm{ZnT}^{+}-\mathrm{PDI}^{-}$) is roughly doubled relative to the yield in the analogous tetrad T-PDI that contains the free base porphyrin in the panchromatic triad unit. The simplest interpretation is that stabilization of the electron-transfer product $\left(\mathrm{ZnT}^{+}-\mathrm{PDI}^{-}\right.$versus $\left.\mathrm{T}^{+}-\mathrm{PDI}^{-}\right)$, together with the higher $\mathrm{S}_{1}$ excited-state energy of $\mathrm{ZnT}^{*}$ versus $\mathrm{T}^{*}$ (Fig. 3 and 4) places the process in the zincated array on a more favorable location on the Marcus rate versus free energy curve.

The analysis now turns to the triads C-P-PDI and ZnC-ZnPPDI in which the central panchromatic triad of the abovementioned pentad (and tetrad benchmarks) is replaced by a porphyrin, albeit one with two phenylethynyl and one ethynylphenyl substituents that renders the porphyrin lowest singlet excited state the $\mathrm{S}_{1}$ excited state of the entire array (vide supra). As noted above, the redox properties of analogous arrays suggest that the central porphyrin in these triads will be harder to oxidize than the panchromatic triad unit in C-T-PDI, T-PDI or ZnT-PDI. The $\Phi_{\mathrm{f}}$ in triad C-P-PDI (0.17) is essentially the same as that in porphyrin benchmark P-TMS/TIPS (0.16) consistent with no excited-state electron transfer. On the other hand, the $\Phi_{\mathrm{f}}$ in triad ZnC-ZnP-PDI (0.04) is reduced by $60 \%$ versus porphyrin benchmark ZnP-H/TIPS (0.10) indicating a substantial yield of excited-state electron transfer. Whether this reflects formation of $\mathrm{ZnC}^{+}-\mathrm{P}^{-}$-PDI or $\mathrm{ZnC}-\mathrm{P}^{+}-\mathrm{PDI}^{-}$or some combination in the first step and whether this is followed by the ground-state process(es) that would produce the $\mathrm{ZnC}^{+}-\mathrm{P}_{-} \mathrm{PDI}^{-}$fully chargeseparated array requires in-depth time-resolved absorption studies, which are beyond the scope of this current work. Regardless, the present studies show that making both the chlorin hole trap and the porphyrin excited-state hole/electron donor simultaneously more easily oxidized compared to the free base porphyrin analogue has a dramatic effect on the photodynamics of the arrays.

\section{Conclusions and outlook}

One target pentad and 11 benchmark compounds were prepared at the $10 \mathrm{mg}$ scale. The two trans- $\mathrm{A}_{2} \mathrm{BC}$ dibromoporphyrin building blocks anchor the star-shaped architecture and were readily accessible through an established " $2+2$ " condensation of dipyrromethanes followed by bromination. A modular strategy was employed for the construction of the arrays, in which several pigment building blocks (porphyrin, chlorin, perylene-diimide, and perylene-monoimide) were readily synthesized and then integrated into arrays via copper-free Pdmediated Sonogashira coupling reactions. This building block approach opens new possibilities for next-generation design and synthesis of molecular systems for studies in the broad field of artificial photosynthesis. The availability of the trans $-\mathrm{A}_{2} \mathrm{BC}$ 
porphyrin building blocks in conjunction with successive Pdmediated coupling reactions provides access to star-shaped architectures that are compositionally richer than those we have prepared previously for light-harvesting and charge separation. ${ }^{64}$ The inclusion of a panchromatic supermolecule constitutes a molecular entity that differs considerably from chromophores found in natural systems.

The absorption spectrum of the pentad array shows panchromatic absorption from below $400 \mathrm{~nm}$ to above $700 \mathrm{~nm}$ due to the central bis(perylene-monoimide)porphyrin unit, complemented by absorption features due to the perylenediimide and chlorin. The latter two constituents can efficiently transfer energy to the central unit and also serve as electron acceptor and hole trap, respectively, for charge separation that is initiated in the core triad. Two chlorin-porphyrinperylene-diimide triads that are capable of charge separation but lack the panchromatic-absorbing core were also prepared as functional benchmarks. The results described herein provide the foundation for in-depth photophysical investigations of all the arrays.

\section{Experimental section}

\section{General methods}

All chemicals obtained commercially were used as received unless otherwise noted. Reagent-grade solvents $\left(\mathrm{CH}_{2} \mathrm{Cl}_{2}, \mathrm{CHCl}_{3}\right.$, methanol, toluene, ethyl acetate) and HPLC-grade solvents (toluene, $\mathrm{CH}_{2} \mathrm{Cl}_{2}$, hexanes) were used as received. ACS-grade hexanes was distilled (with a rotary evaporator) and dried (over $4 \AA$ molecular sieves) immediately before use. THF was freshly distilled from sodium/benzophenone ketyl and used immediately. Matrix-assisted laser-desorption ionization mass spectrometry (MALDI-MS) was performed with the matrix 1,4bis(5-phenyl-2-oxaxol-2-yl)benzene (POPOP) ${ }^{65}$ unless noted otherwise. ESI-MS data are reported for the molecular ion or cationized molecular ion. Noncommercial compounds $1,{ }^{57} 3,{ }^{56}$ $5,{ }^{60} \mathbf{Z n} 5^{60}$ and $8^{34}$ were prepared following literature procedures, whereas the known dipyrromethane 1-TMS ${ }^{58}$ was synthesized following a more recent method. ${ }^{57}$ All other compounds were used as received from commercial sources.

\section{Chromatography}

A sequence of three-chromatography procedures ${ }^{31}$ was employed for purification of arrays following Pd-mediated coupling reactions. First, adsorption column chromatography (flash silica, Silicycle) was applied to remove catalysts and other materials. Second, preparative-scale SEC was applied. A glass column (o.d. $4.3 \mathrm{~cm}$ ) was packed using BioRad Bio-Beads S-X1 $(\mathrm{MWCO}=12000 \mathrm{Da})$ in HPLC-grade toluene with a length of $53 \mathrm{~cm}$. The chromatography was performed with gravity flow ( $\sim 1$ drop per s). Eluate was collected in $3 \mathrm{~mL}$ portions and analyzed with MALDI-MS and absorption spectrometry. The portion with the desired product was combined and concentrated. Third, adsorption column chromatography (flash silica, Silicycle) was performed with HPLC-grade $\mathrm{CH}_{2} \mathrm{Cl}_{2}$ and $n$-hexane unless noted otherwise.
Analytical-scale SEC (styrene-divinylbenzene copolymer columns) was performed to characterize the purity of the resulting samples. Analytical SEC was performed with $100 \AA$, $500 \AA$, and $1000 \AA$ columns in series eluting with HPLC-grade

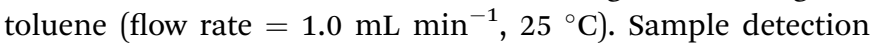
was achieved by absorption spectroscopy using a diode-array detector $\left(\lambda_{\mathrm{det}}=430,476,537,638 \mathrm{~nm}\right)$.

\section{General procedure for Pd-catalyzed coupling reactions}

Toluene (or THF) and TEA were deaerated by bubbling with argon for $1 \mathrm{~h}$. The solid starting materials, including $\mathrm{Pd}_{2}(\mathrm{dba})_{3}$ and $\mathrm{P}(o \text {-tol })_{3}$, were charged in a Schlenk flask. The flask was evacuated under high vacuum for $5 \mathrm{~min}$, then purged with argon. The evacuation-purge procedure was repeated three times. The deaerated solvents were then added to the Schlenk flask via a syringe. The resulting mixture was again deaerated by three freeze-pump-thaw cycles. Then liquid reagents, if any, were added to the flask. The mixture was then heated to initiate reaction. The copper-free method has been described in detail. $^{54,55}$

\section{5-Phenyl-15-[4-(2-trimethylsilylethynyl)phenyl] porphyrinatozinc(II) (Zn2-TMS)}

Following a reported method, ${ }^{56}$ a solution of diacyldipyrromethane 1 (42 mg, $0.15 \mathrm{mmol})$ in THF $(0.50 \mathrm{~mL})$ was treated with propylamine $(0.18 \mathrm{~g}, 3.0 \mathrm{mmol})$ and stirred at room temperature for $1 \mathrm{~h}$. The solution was concentrated to dryness. The resulting solid was dissolved in ethanol $(15 \mathrm{~mL})$ and treated with dipyrromethane 1-TMS (48 mg, $0.15 \mathrm{mmol}$ ) and $\mathrm{Zn}(\mathrm{OAc})_{2}$ $(0.28 \mathrm{~g}, 1.5 \mathrm{mmol})$. The mixture was then refluxed open to the air for $18 \mathrm{~h}$. Upon cooling to room temperature, the mixture was concentrated and chromatographed [silica gel, hexanes $/ \mathrm{CH}_{2} \mathrm{Cl}_{2}$ (2:1)] to afford a purple solid (37 mg, 40\%): ${ }^{1} \mathrm{H}$ NMR (THF- $d_{8}$, $400 \mathrm{MHz}) \delta 10.28$ (s, 2H), $9.40(\mathrm{~d}, J=4.4 \mathrm{~Hz}, 4 \mathrm{H}), 9.02(\mathrm{~d}, J=$ $4.4 \mathrm{~Hz}, 4 \mathrm{H}), 8.21-8.23$ (m, 4H), 7.78-7.88 (m, 5H), 0.38 (s, 9H); ${ }^{13} \mathrm{C}$ NMR $\left(\right.$ THF- $\left.d_{8}, 100 \mathrm{MHz}\right) \delta 150.9,150.6,150.5,144.9,144.3$, 135.6, 132.7, 132.3, 130.8, 128.1, 127.2, 123.2, 120.5, 119.2, 106.63, 106.56, 106.4, 95.2, 0.127; MALDI-MS obsd $620.7\left[\mathrm{M}^{+}\right]$, ESI-MS obsd $621.1428\left[(\mathrm{M}+\mathrm{H})^{+}\right]$, calcd $620.1375\left(\mathrm{M}=\mathrm{C}_{37} \mathrm{H}_{28^{-}}\right.$ $\left.\mathrm{N}_{4} \mathrm{SiZn}\right) ; \lambda_{\text {abs }}\left(\mathrm{CH}_{2} \mathrm{Cl}_{2}\right) 409,536,572 \mathrm{~nm}$.

\section{5-Phenyl-15-[4-(2-trimethylsilylethynyl)phenyl]porphyrin (2-TMS)}

Following a reported $\operatorname{method}^{\mathbf{4 3}}$ with slight modifications, a solution of zinc porphyrin Zn2-TMS (33 $\mathrm{mg}, 0.053 \mathrm{mmol}$ ) in $\mathrm{CHCl}_{3}(50 \mathrm{~mL})$ was treated dropwise with trifluoroacetic acid (0.20 mL, $1.2 \mathrm{mmol})$. The solution was stirred at room temperature for $30 \mathrm{~min}$. Then the reaction was quenched by the addition of saturated aqueous $\mathrm{NaHCO}_{3}$ solution. The mixture was extracted with $\mathrm{CH}_{2} \mathrm{Cl}_{2}$. The organic extract was washed with brine, dried with $\mathrm{Na}_{2} \mathrm{SO}_{4}$, concentrated and chromatographed [silica gel, hexanes $/ \mathrm{CH}_{2} \mathrm{Cl}_{2}(2: 1)$ ] to afford a purple solid (17 mg, 58\%): ${ }^{1} \mathrm{H}$ NMR (THF- $\left.d_{8}, 300 \mathrm{MHz}\right) \delta 10.38$ (s, 2H), 9.44 (m, 4H), $9.04(\mathrm{~m}, 4 \mathrm{H}), 8.22-8.26(\mathrm{~m}, 4 \mathrm{H}), 7.82-7.94(\mathrm{~m}, 5 \mathrm{H}), 0.38$ $(\mathrm{s}, 9 \mathrm{H}),-3.12(\mathrm{br}, 2 \mathrm{H}) ;{ }^{13} \mathrm{C}$ NMR $\left(\mathrm{THF}-d_{8}, 100 \mathrm{MHz}\right) \delta 150.8$, 150.6 , 150.5, 148.1, 147.8, 146.3, 142.9, 142.4, 135.7, 132.8, 
$132.7,132.6,132.5,131.6,131.3,131.2,128.6,127.8,123.7$, 120.0, 118.7, 106.2, 106.1, 95.6, 0.127; MALDI-MS obsd 558.4 $\left[\mathrm{M}^{+}\right]$, ESI-MS obsd 559.2326 $\left[(\mathrm{M}+\mathrm{H})^{+}\right]$, calcd $558.2240(\mathrm{M}=$ $\left.\mathrm{C}_{37} \mathrm{H}_{30} \mathrm{~N}_{4} \mathrm{Si}\right) ; \lambda_{\text {abs }}\left(\mathrm{CH}_{2} \mathrm{Cl}_{2}\right) 406,503,537,575,630 \mathrm{~nm}$.

\section{0,20-Dibromo-5-phenyl-15-[4-(2-trimethylsilylethynyl)phenyl] porphyrin (2-Br 2 /TMS)}

Following a standard bromination method, ${ }^{59}$ a solution of porphyrin 2-TMS (12 mg, $0.021 \mathrm{mmol})$ in $\mathrm{CHCl}_{3}(6.8 \mathrm{~mL})$ containing pyridine $(9.0 \mu \mathrm{L})$ was cooled to $0{ }^{\circ} \mathrm{C}$ and treated with NBS (9.2 mg, $0.052 \mathrm{mmol}$ ). The mixture was stirred at $0{ }^{\circ} \mathrm{C}$ for $1 \mathrm{~h}$. The reaction was quenched by the addition of saturated aqueous $\mathrm{NaHCO}_{3}$ solution. The mixture was extracted with $\mathrm{CH}_{2} \mathrm{Cl}_{2}$. The organic extract was washed with brine, dried with $\mathrm{Na}_{2} \mathrm{SO}_{4}$, concentrated, and chromatographed [silica gel, hexanes $\left./ \mathrm{CH}_{2} \mathrm{Cl}_{2}(4: 1)\right]$ to afford a purple-red solid (11 mg, 74\%): ${ }^{1} \mathrm{H}$ NMR (THF- $\left.d_{8}, 300 \mathrm{MHz}\right) \delta 9.62(\mathrm{~d}, J=4.5 \mathrm{~Hz}, 4 \mathrm{H}), 8.82$ $(\mathrm{d}, J=4.5 \mathrm{~Hz}, 4 \mathrm{H}), 8.12-8.16(\mathrm{~m}, 4 \mathrm{H}), 7.78-7.89(\mathrm{~m}, 5 \mathrm{H}), 0.38(\mathrm{~s}$, $9 \mathrm{H}),-2.74(\mathrm{~s}, 2 \mathrm{H}) ;{ }^{13} \mathrm{C}$ NMR (THF- $\left.d_{8}, 100 \mathrm{MHz}\right) \delta 142.6,142.3$, 135.4, 131.2 , 129.0, 127.8, 124.2, 122.7, 121.5, 105.9, 104.2, 95.9, 0.089; MALDI-MS obsd 717.1 [(M + H $\left.)^{+}\right]$, ESI-MS 715.0520 [(M + $\mathrm{H})^{+}$, calcd $714.0405\left(\mathrm{M}=\mathrm{C}_{37} \mathrm{H}_{28} \mathrm{Br}_{2} \mathrm{~N}_{4} \mathrm{Si}\right) ; \lambda_{\text {abs }}\left(\mathrm{CH}_{2} \mathrm{Cl}_{2}\right)$ 422, 485, 520, 557, $661 \mathrm{~nm}$.

\section{5-(4-Iodophenyl)-15-[4-(2-trimethylsilylethynyl)phenyl] porphyrinatozinc(II) (Zn4-I/TMS)}

Following a reported method, ${ }^{56}$ a solution of diformyldipyrromethane-tin complex $3(0.40 \mathrm{~g}, 0.63 \mathrm{mmol})$ in propylamine $(1.0$ $\mathrm{mL}$ ) was stirred at room temperature for $2 \mathrm{~h}$ and then concentrated to dryness. A solution of the resulting solid and $\mathrm{Zn}(\mathrm{OAc})_{2}$ $(1.20 \mathrm{~g}, 6.3 \mathrm{mmol})$ in ethanol $(63 \mathrm{~mL})$ was refluxed open to the air for $17 \mathrm{~h}$. The cooled mixture was passed through a pad of silica gel $\left(\mathrm{CH}_{2} \mathrm{Cl}_{2}\right)$, concentrated, and chromatographed [silica gel, hexanes/ethyl acetate $(4: 1)]$ to afford a purple-red solid (73 mg, 15\%): ${ }^{1} \mathrm{H}$ NMR (THF- $\left.d_{8}, 300 \mathrm{MHz}\right) \delta 10.29$ (s, 2H), 9.42 $(\mathrm{d}, J=4.4 \mathrm{~Hz}, 4 \mathrm{H}), 9.02(\mathrm{dd}, J=5.6,4.4 \mathrm{~Hz}, 4 \mathrm{H}), 8.22(\mathrm{~d}, J=$ $8.0 \mathrm{~Hz}, 2 \mathrm{H}), 8.16(\mathrm{~d}, J=8.0 \mathrm{~Hz}, 2 \mathrm{H}), 8.02(\mathrm{~d}, J=8.0 \mathrm{~Hz}, 2 \mathrm{H}), 7.88$ $(\mathrm{d}, J=8.0 \mathrm{~Hz}, 2 \mathrm{H}), 0.38(\mathrm{~s}, 9 \mathrm{H})$; MALDI-MS obsd $748.0[(\mathrm{M}+$ $\left.\mathrm{H})^{+}\right]$, ESI-MS obsd $747.0392\left[(\mathrm{M}+\mathrm{H})^{+}\right]$, calcd $747.0414(\mathrm{M}=$ $\left.\mathrm{C}_{37} \mathrm{H}_{27} \mathrm{IN}_{4} \mathrm{SiZn}\right) ; \lambda_{\text {abs }}\left(\mathrm{CH}_{2} \mathrm{Cl}_{2}\right) 411,538,572 \mathrm{~nm}$.

\section{5-[4-(2-Triisopropylsilylethynyl)phenyl]-15-[4-(2- trimethylsilylethynyl)phenyl]porphyrinatozinc(II) (Zn4-TMS/ TIPS)}

Following the general procedure for Pd-catalyzed coupling reactions described above, a mixture of Zn4-I/TMS (67 mg, 0.090 $\mathrm{mmol}), \mathrm{PdCl}_{2}\left(\mathrm{PPh}_{3}\right)_{2}(3.2 \mathrm{mg}, 4.5 \mu \mathrm{mol})$, and $\mathrm{CuI}(1.7 \mathrm{mg}, 1.0$ $\mu \mathrm{mol})$ in THF/TEA $(9: 1,9.0 \mathrm{~mL})$ was treated with TIPSacetylene $(0.100 \mathrm{~mL}, 0.45 \mathrm{mmol})$ under argon and then stirred at $60{ }^{\circ} \mathrm{C}$ for $4 \mathrm{~h}$. The reaction was quenched by the addition of water. The mixture was extracted with $\mathrm{CH}_{2} \mathrm{Cl}_{2}$. The organic extract was washed with brine, dried, concentrated, and chromatographed [silica gel, hexanes/ethyl acetate $(9: 1)]$ to afford a red solid (58 mg, 80\%): ${ }^{1} \mathrm{H}$ NMR (THF- $\left.d_{8}, 300 \mathrm{MHz}\right) \delta 10.29(\mathrm{~s}$, $2 \mathrm{H}), 9.42$ (d, $J=4.5 \mathrm{~Hz}, 4 \mathrm{H}), 9.02(\mathrm{dd}, J=7.2,4.8 \mathrm{~Hz}, 4 \mathrm{H}), 8.22$ (dd, $J=7.8,1.8 \mathrm{~Hz}, 4 \mathrm{H}), 7.89$ (dd, $J=9.9,7.8 \mathrm{~Hz}, 4 \mathrm{H}), 1.50$ (m,
3H), 1.10 (m, 18H), 0.37 (s, 9H); MALDI-MS obsd $802.4[(\mathrm{M}+$ $\left.\mathrm{H})^{+}\right]$, ESI-MS obsd 801.2775 [(M+ H $\left.)^{+}\right]$, calcd $801.2782(\mathrm{M}=$ $\left.\mathrm{C}_{48} \mathrm{H}_{48} \mathrm{~N}_{4} \mathrm{Si}_{2} \mathrm{Zn}\right) ; \lambda_{\text {abs }}\left(\mathrm{CH}_{2} \mathrm{Cl}_{2}\right) 411,538,576 \mathrm{~nm}$.

5,15-Dibromo-10-[4-(2-triisopropylsilylethynyl)phenyl]-20-[4(2-trimethylsilylethynyl)phenyl]porphyrin (4-Br 2 /TMS/TIPS)

A solution of Zn4-TMS/TIPS (54 mg, $67 \mu \mathrm{mol}$ ) in $\mathrm{CH}_{2} \mathrm{Cl}_{2}(22 \mathrm{~mL}$ ) containing pyridine $(0.030 \mathrm{~mL}, 0.33 \mathrm{mmol})$ was treated with NBS $(0.030 \mathrm{~g}, 0.17 \mathrm{mmol})$ at $0{ }^{\circ} \mathrm{C}$ for $1 \mathrm{~h}$. The solution was allowed to warm to room temperature and then treated with saturated aqueous $\mathrm{NH}_{4} \mathrm{Cl}$ solution. The mixture was extracted with $\mathrm{CH}_{2} \mathrm{Cl}_{2}$. The organic extract was washed with brine, dried, and concentrated to dryness. A solution of the resulting solid in $\mathrm{CH}_{2} \mathrm{Cl}_{2}(40 \mathrm{~mL})$ was treated dropwise with trifluoroacetic acid $(0.26 \mathrm{~mL}, 3.4 \mathrm{mmol})$ and stirred at room temperature for $30 \mathrm{~min}$. The reaction was quenched by the addition of saturated aqueous $\mathrm{NaHCO}_{3}$ solution. The mixture was extracted with $\mathrm{CH}_{2} \mathrm{Cl}_{2}$. The organic extract was washed with brine, dried, concentrated and chromatographed [silica gel, hexanes $/ \mathrm{CH}_{2} \mathrm{Cl}_{2}$ (3:1)] to afford a red solid (16 mg, 27\%): ${ }^{1} \mathrm{H}$ NMR (THF- $d_{8}, 300$ $\mathrm{MHz}) \delta 9.64(\mathrm{~d}, J=5.1 \mathrm{~Hz}, 4 \mathrm{H}), 8.84-8.87(\mathrm{~m}, 4 \mathrm{H}), 8.14(\mathrm{~d}, J=$ $7.8 \mathrm{~Hz}, 4 \mathrm{H}), 7.90(\mathrm{~m}, 4 \mathrm{H}), 1.49$ (m, 3H) 1.29, (s, 18H), 0.37 (s, $9 \mathrm{H}),-2.74(\mathrm{~s}, 2 \mathrm{H})$; MALDI-MS obsd $896.6\left[(\mathrm{M}+\mathrm{H})^{+}\right]$, ESI-MS obsd 895.1836 $\left[(\mathrm{M}+\mathrm{H})^{+}\right]$, calcd $895.1857\left(\mathrm{M}=\mathrm{C}_{48} \mathrm{H}_{48} \mathrm{Br}_{2} \mathrm{~N}_{4^{-}}\right.$ $\left.\mathrm{Si}_{2}\right) ; \lambda_{\text {abs }}\left(\mathrm{CH}_{2} \mathrm{Cl}_{2}\right) 429,524,562,605,659 \mathrm{~nm}$.

\section{5-(4-Ethynylphenyl)-10,20-bis(2-phenylethynyl)-15-[4-(2- triisopropylsilylethynyl)phenyl]porphyrinatozinc(II) (ZnP-H/ TIPS)}

A solution of Zn4-TMS/TIPS (118 mg, $0.146 \mathrm{mmol}, 1.0$ equiv.) in $\mathrm{CH}_{2} \mathrm{Cl}_{2}$ (49 $\mathrm{mL}$, [Zn4-TMS/TIPS] $3 \mathrm{mM}$ ) containing pyridine ( $65 \mu \mathrm{L}, 0.81 \mathrm{mmol}, 5.5$ equiv.) was cooled to $0{ }^{\circ} \mathrm{C}$ under argon, and treated with NBS (65 mg, $0.37 \mathrm{mmol}, 2.5$ equiv.) at $0{ }^{\circ} \mathrm{C}$ for $1 \mathrm{~h}$. The reaction was then quenched by the addition of saturated aqueous $\mathrm{NaHCO}_{3}$ solution. The mixture was extracted with $\mathrm{CH}_{2} \mathrm{Cl}_{2}$. The organic extract was dried, concentrated, and chromatographed (silica gel, hexanes $/ \mathrm{CH}_{2} \mathrm{Cl}_{2}=1: 1$ ) to afford a blue solid (140 mg): TLC (silica, hexanes $\left./ \mathrm{CH}_{2} \mathrm{Cl}_{2}=1: 1\right) R_{\mathrm{f}}=$ 0.28 ; MALDI-MS obsd $957.0\left[(\mathrm{M}+\mathrm{H})^{+}\right]$. Following the general procedure for Pd-catalyzed coupling reactions described above, a mixture of the resulting solid $(140 \mathrm{mg}, 0.146 \mathrm{mmol}, 1.0$ equiv.), phenylacetylene ( $35 \mu \mathrm{L}, 0.32 \mathrm{mmol}, 2.2$ equiv.), $\mathrm{Pd}_{2}(\mathrm{dba})_{3}$ (40 mg, $0.044 \mathrm{mmol}, 0.30$ equiv.), $\mathrm{P}(o \text {-tol })_{3}$ (107 mg, $0.350 \mathrm{mmol}, 2.4$ equiv.), and $\mathrm{CuI}(1.4 \mathrm{mg}, 7.3 \mu \mathrm{mol}, 0.050$ equiv.) in deaerated THF/TEA $(5: 1,14.6 \mathrm{~mL})$ was stirred at $60^{\circ} \mathrm{C}$ for $17 \mathrm{~h}$. The mixture was allowed to cool to room temperature, dried, and chromatographed (silica gel, hexanes $/ \mathrm{CH}_{2} \mathrm{Cl}_{2}=2: 1$ to $3: 2$ ) to afford a blue solid (72.6 mg): TLC (silica, hexanes/ $\left.\mathrm{CH}_{2} \mathrm{Cl}_{2}=3: 2\right) R_{\mathrm{f}}=0.30$; MALDI-MS obsd $1001.9\left[(\mathrm{M}+\mathrm{H})^{+}\right]$. Then, a mixture of the resulting solid $(72.6 \mathrm{mg})$ and $\mathrm{K}_{2} \mathrm{CO}_{3}$ (1.00 g, $7.24 \mathrm{mmol}, 100$ equiv.) in $\mathrm{THF} / \mathrm{CH}_{3} \mathrm{OH}(1: 1,15 \mathrm{~mL})$ was stirred at room temperature for $3 \mathrm{~h}$. MALDI-MS analysis showed the completion of the reaction [obsd 929.8, $\left.\left[(\mathrm{M}+\mathrm{H})^{+}\right]\right]$. The reaction was then quenched by the addition of water. The mixture was extracted with $\mathrm{CH}_{2} \mathrm{Cl}_{2}$. The organic extract was dried, concentrated, and chromatographed (silica gel, hexanes/ 
$\mathrm{CH}_{2} \mathrm{Cl}_{2}=3: 2$ to $\left.1: 1\right)$ to afford a blue solid $(60.2 \mathrm{mg}, 44 \%$ for three steps): ${ }^{1} \mathrm{H}$ NMR (THF- $\left.d_{8}, 400 \mathrm{MHz}\right) \delta 9.76(\mathrm{~d}, J=4.3 \mathrm{~Hz}$, $4 \mathrm{H}), 8.86(\mathrm{~d}, J=4.7 \mathrm{~Hz}, 4 \mathrm{H}), 8.20-7.47(\mathrm{~m}, 18 \mathrm{H}), 3.28(\mathrm{~s}, 1 \mathrm{H})$, 1.30-1.22 (m, 21H); MALDI-MS obsd $929.8\left[(\mathrm{M}+\mathrm{H})^{+}\right]$, ESI-MS obsd $929.3038\left[(\mathrm{M}+\mathrm{H})^{+}\right]$, calcd $929.3012\left(\mathrm{M}=\mathrm{C}_{61} \mathrm{H}_{48} \mathrm{~N}_{4} \mathrm{SiZn}\right)$.

\section{0-Mesityl-18,18-dimethyl-5-(4-(2-phenylethynyl)phenyl) chlorin (C-Ph)}

Following the general procedure for Pd-catalyzed coupling reactions described above, a solution of Zn5 $(5.0 \mathrm{mg}, 6.9 \mu \mathrm{mol})$ in THF/TEA $(9: 1,0.70 \mathrm{~mL})$ was treated with phenylacetylene $(3.8 \mu \mathrm{L}, 0.034 \mathrm{mmol})$ in the presence of $\mathrm{PdCl}_{2}\left(\mathrm{PPh}_{3}\right)_{2}(0.70 \mathrm{mg}$, $1.0 \mu \mathrm{mol})$ and $\mathrm{CuI}(0.20 \mathrm{mg}, 1.0 \mu \mathrm{mol})$ and stirred at $60^{\circ} \mathrm{C}$ for $24 \mathrm{~h}$. The reaction was quenched by the addition of water. The mixture was extracted with $\mathrm{CH}_{2} \mathrm{Cl}_{2}$. The organic extract was washed with brine, dried, and concentrated. A solution of the resulting sample in $\mathrm{CH}_{2} \mathrm{Cl}_{2}(4.1 \mathrm{~mL})$ was treated dropwise with trifluoroacetic acid $(0.027 \mathrm{~mL})$ and stirred at room temperature for $30 \mathrm{~min}$. The reaction was quenched by the addition of saturated aqueous $\mathrm{NaHCO}_{3}$ solution. The mixture was extracted with $\mathrm{CH}_{2} \mathrm{Cl}_{2}$. The organic extract was washed with brine, dried, concentrated, and chromatographed [silica gel, hexanes $/ \mathrm{CH}_{2} \mathrm{Cl}_{2}$ $(3: 1)]$ to afford a green solid $(3.7 \mathrm{mg}, 84 \%):{ }^{1} \mathrm{H}$ NMR $\left(\mathrm{CDCl}_{3}\right.$, $300 \mathrm{MHz}) \delta 8.93(\mathrm{~s}, 1 \mathrm{H}), 8.86(\mathrm{~s}, 1 \mathrm{H}), 8.83(\mathrm{~d}, J=4.5 \mathrm{~Hz}, 1 \mathrm{H})$, 8.74-8.76 (m, 2H), $8.60(\mathrm{~d}, J=4.5 \mathrm{~Hz}, 1 \mathrm{H}), 8.43(\mathrm{~d}, J=4.5 \mathrm{~Hz}$, $1 \mathrm{H}), 8.46(\mathrm{~d}, J=4.5 \mathrm{~Hz}, 1 \mathrm{H}), 8.08(\mathrm{~d}, J=8.1 \mathrm{~Hz}, 2 \mathrm{H}), 7.69(\mathrm{~d}, J=$ $8.1 \mathrm{~Hz}, 2 \mathrm{H}), 7.55-7.58(\mathrm{~m}, 2 \mathrm{H}), 7.32-7.34(\mathrm{~m}, 3 \mathrm{H}), 7.23(\mathrm{~s}, 2 \mathrm{H})$, $4.60(\mathrm{~s}, 2 \mathrm{H}), 2.59(\mathrm{~s}, 3 \mathrm{H}), 2.06(\mathrm{~s}, 6 \mathrm{H}), 1.84(\mathrm{~s}, 6 \mathrm{H}),-1.83(\mathrm{~s}, 2 \mathrm{H})$; MALDI-MS obsd $634.8\left[\mathrm{M}^{+}\right]$, ESI-MS obsd $635.3169\left[(\mathrm{M}+\mathrm{H})^{+}\right]$, calcd 634.3096 $\left(\mathrm{M}=\mathrm{C}_{45} \mathrm{H}_{38} \mathrm{~N}_{4}\right)$; $\lambda_{\text {abs }}$ (toluene) 414, 508, 589, $641 \mathrm{~nm}$.

\section{$N$-(4-Iodophenyl)- $N^{\prime}$-(2,6-diisopropylphenyl)perylene-3,4,9,10- bis(dicarboximide) (7)}

Following a reported procedure, ${ }^{37}$ a mixture of $6(3.00 \mathrm{~g}, 7.64$ $\mathrm{mmol})$, 2,6-diisopropylaniline ( $4.3 \mathrm{~mL}, 23 \mathrm{mmol})$, 4-iodoaniline (3.35 g, $15 \mathrm{mmol}), \mathrm{Zn}(\mathrm{OAc})_{2}$ (1.05 g), and imidazole (22.5 g) was heated to $190{ }^{\circ} \mathrm{C}$ under argon. After $20 \mathrm{~h}$, the mixture was allowed to cool to room temperature and then was treated with $60 \%$ ethanol $(180 \mathrm{~mL})$ for another $2 \mathrm{~h}$. The suspension was then filtered. The filter cake was washed with $60 \%$ ethanol. The dry sample was suspended in $10 \%$ aqueous $\mathrm{KOH}$ solution and refluxed for $30 \mathrm{~min}$. Upon cooling to room temperature, the mixture was filtered. The filter cake was washed with water and dried in an oven. The resulting solid was soaked in $\mathrm{CH}_{2} \mathrm{Cl}_{2}(100$ $\mathrm{mL}$ ), sonicated for $5 \mathrm{~min}$, and filtered to remove insoluble perylene-diimide byproducts. The $\mathrm{CH}_{2} \mathrm{Cl}_{2}$ filtrate was concentrated and chromatographed [silica gel, hexanes/ethyl acetate ( $7: 1$ to $7: 3)]$ to afford a red solid $(1.52 \mathrm{~g}, 30 \%):{ }^{1} \mathrm{H}$ NMR $\left(\mathrm{CDCl}_{3}, 300 \mathrm{MHz}\right) \delta 8.66-8.80(\mathrm{~m}, 8 \mathrm{H}), 7.91(\mathrm{dd}, J=6.6,1.8 \mathrm{~Hz}$, $2 \mathrm{H}), 7.51(\mathrm{t}, J=7.5 \mathrm{~Hz}, 1 \mathrm{H}), 7.36(\mathrm{~d}, J=7.5 \mathrm{~Hz}, 2 \mathrm{H}), 7.12(\mathrm{dd}, J=$ $6.6,1.8 \mathrm{~Hz}, 2 \mathrm{H}$ ), 2.76 (quintet, $J=6.6 \mathrm{~Hz}, 2 \mathrm{H}), 1.18(\mathrm{~d}, J=6.6 \mathrm{~Hz}$, 12H); MALDI-MS obsd 754.0 [(M + H $\left.)^{+}\right]$, ESI-MS obsd 753.1235 $\left[(\mathrm{M}+\mathrm{H})^{+}\right]$, calcd $752.1172\left(\mathrm{M}=\mathrm{C}_{49} \mathrm{H}_{29} \mathrm{IN}_{2} \mathrm{O}_{4}\right) ; \lambda_{\mathrm{abs}}\left(\mathrm{CH}_{2} \mathrm{Cl}_{2}\right) 434$, 459, 490, $527 \mathrm{~nm}$.

\section{$N$-[4-(2-Phenylethynyl)phenyl]- $N^{\prime}$-(2,6-diisopropylphenyl)} perylene-3,4,9,10-bis(dicarboximide) (PDI-Ph)

Following the general procedure for Pd-catalyzed coupling reactions described above, a solution of $7(3.0 \mathrm{mg}, 4.0 \mu \mathrm{mol})$ in toluene/TEA $(5: 1,1.8 \mathrm{~mL})$ was treated with phenylacetylene $(2.2 \mu \mathrm{L}, 0.020 \mathrm{mmol})$ in the presence of $\mathrm{PdCl}_{2}\left(\mathrm{PPh}_{3}\right)_{2}(0.50 \mathrm{mg}$, $0.60 \mu \mathrm{mol})$ and $\mathrm{CuI}(0.10 \mathrm{mg}, 0.60 \mu \mathrm{mol})$ and stirred at $60^{\circ} \mathrm{C}$ for $3 \mathrm{~h}$. Then the reaction was quenched by the addition of water. The mixture was extracted with $\mathrm{CH}_{2} \mathrm{Cl}_{2}$. The organic extract was washed with brine, dried, concentrated, and chromatographed [silica gel, hexanes/ethyl acetate $(7: 3)$ ] to afford a red solid (1.5 mg, 52\%): ${ }^{1} \mathrm{H} \mathrm{NMR}\left(\mathrm{CDCl}_{3}, 300 \mathrm{MHz}\right) \delta 8.69-8.81(\mathrm{~m}, 8 \mathrm{H})$, $7.73(\mathrm{~d}, J=8.7 \mathrm{~Hz}, 2 \mathrm{H}), 7.49-7.59(\mathrm{~m}, 3 \mathrm{H}), 7.35-7.40(\mathrm{~m}, 7 \mathrm{H})$, 2.76 (pentad, $J=6.9 \mathrm{~Hz}, 2 \mathrm{H}), 1.19$ (d, $J=6.9 \mathrm{~Hz}, 12 \mathrm{H}$ ); MALDIMS obsd $726.1\left[\mathrm{M}^{+}\right]$, ESI-MS 727.2553 [(M+ $\left.\left.\mathrm{H}^{+}\right)\right]$, calcd 726.2519 $\left(\mathrm{M}=\mathrm{C}_{50} \mathrm{H}_{34} \mathrm{~N}_{2} \mathrm{O}_{4}\right) ; \lambda_{\text {abs }}$ (toluene) 459, 491, $527 \mathrm{~nm}$.

5,15-Bis[2-(3,4-( $N$-(2,6-diisopropylphenyl)iminodicarbonyl)1,6-bis(4-tert-butylphenoxy)perylen-9-yl)ethynyl]-10-phenyl20-(4-(2-trimethylsilylethynyl)phenyl)porphyrin (T-Ph)

Following the general procedure for Pd-catalyzed coupling reactions described above, a mixture of porphyrin $2-\mathbf{B r}_{2} / \mathbf{T M S}$ (5.4 mg, $7.5 \mu \mathrm{mol}), 8$ (12 mg, $0.015 \mathrm{mmol}), \mathrm{Pd}_{2}(\mathrm{dba})_{3}(2.1 \mathrm{mg}$, $2.2 \mu \mathrm{mol})$, and $\mathrm{P}(o \text {-tol })_{3}(5.5 \mathrm{mg}, 18 \mu \mathrm{mol})$ in toluene/TEA $(5: 1$, $3.4 \mathrm{~mL}$ ) was stirred at $60^{\circ} \mathrm{C}$ for $4 \mathrm{~h}$. The mixture was allowed to cool to room temperature and then was purified according to the three-chromatography method. The product was concentrated to afford a black solid (14 mg, 86\%): ${ }^{1} \mathrm{H}$ NMR $\left(\mathrm{CDCl}_{3}, 300\right.$ MHz): $\delta 9.73(\mathrm{~d}, J=5.1 \mathrm{~Hz}, 4 \mathrm{H}) ; 9.27$ (d, $J=7.2 \mathrm{~Hz}, 2 \mathrm{H}), 9.21(\mathrm{~d}, J$ $=7.8 \mathrm{~Hz}, 2 \mathrm{H}), 9.02(\mathrm{~d}, J=8.1 \mathrm{~Hz}, 2 \mathrm{H}), 8.86(\mathrm{~d}, J=5.1 \mathrm{~Hz}, 2 \mathrm{H})$, $8.80(\mathrm{~d}, J=5.1 \mathrm{~Hz}, 2 \mathrm{H}), 8.33(\mathrm{~s}, 2 \mathrm{H}), 8.28(\mathrm{~s}, 2 \mathrm{H}), 8.20-8.10(\mathrm{~m}$, $4 \mathrm{H}), 7.90(\mathrm{~d}, J=7.8 \mathrm{~Hz}, 2 \mathrm{H}), 7.79(\mathrm{~m}, 3 \mathrm{H}), 7.67(\mathrm{t}, J=7.8 \mathrm{~Hz}, 2 \mathrm{H})$, $7.39-7.49(\mathrm{~m}, 12 \mathrm{H}), 7.32(\mathrm{~d}, J=7.8 \mathrm{~Hz}, 4 \mathrm{H}), 7.08(\mathrm{~d}, J=9.0 \mathrm{~Hz}$, $4 \mathrm{H}), 7.05(\mathrm{~d}, J=9.0 \mathrm{~Hz}, 4 \mathrm{H}), 2.77$ (quintet, $J=6.6 \mathrm{~Hz}, 4 \mathrm{H}), 1.34$ $(\mathrm{s}, 36 \mathrm{H}), 1.18(\mathrm{~d}, J=6.6 \mathrm{~Hz}, 24 \mathrm{H}), 0.089(\mathrm{~s}, 9 \mathrm{H}),-1.90(\mathrm{~s}, 2 \mathrm{H})$; MALDI-MS obsd 2158.0 [( $\left.\mathrm{M}+\mathrm{H})^{+}\right]$, calcd $2156.9563(\mathrm{M}=$ $\mathrm{C}_{149} \mathrm{H}_{128} \mathrm{~N}_{6} \mathrm{O}_{8} \mathrm{Si}$ ); $\lambda_{\text {abs }}$ (toluene) 429, 476, 537, 638, $726 \mathrm{~nm}$.

\section{5,15-Bis[2-(3,4-( $N$-(2,6-diisopropylphenyl)iminodicarbonyl)- 1,6-bis(4-tert-butylphenoxy)perylen-9-yl)ethynyl]-10-phenyl- 20-(4-(2-trimethylsilylethynyl)phenyl)porphyrinatozinc(II) (ZnT-Ph)}

A solution of T-Ph $(22 \mathrm{mg}, 10 \mu \mathrm{mol})$ was treated with $\mathrm{Zn}(\mathrm{OAc})_{2} \cdot 2 \mathrm{H}_{2} \mathrm{O}(44 \mathrm{mg}, 0.20 \mathrm{mmol})$ in $\mathrm{CH}_{2} \mathrm{Cl}_{2} / \mathrm{CH}_{3} \mathrm{OH}(2: 1,3.0$ $\mathrm{mL}$ ) for $18 \mathrm{~h}$. The resulting mixture was washed with water. The organic layer was dried and purified according to the threechromatography method to afford a black solid (10 mg, 45\%): ${ }^{1} \mathrm{H}$ NMR $\left(\mathrm{CDCl}_{3}, 300 \mathrm{MHz}\right): \delta 9.77(\mathrm{~m}, 4 \mathrm{H}) ; 9.30-9.00(\mathrm{~m}, 6 \mathrm{H})$, 8.90-8.82 (m, 4H), $8.35(\mathrm{~s}, 2 \mathrm{H}), 8.27(\mathrm{~s}, 2 \mathrm{H}), 8.22-8.10(\mathrm{~m}, 4 \mathrm{H})$, $7.90-7.65(\mathrm{~m}, 7 \mathrm{H}), 7.39-7.49(\mathrm{~m}, 12 \mathrm{H}), 7.34(\mathrm{~d}, J=8.1 \mathrm{~Hz}, 4 \mathrm{H})$, $7.08(\mathrm{~d}, J=8.7 \mathrm{~Hz}, 4 \mathrm{H}), 7.07(\mathrm{~d}, J=8.6 \mathrm{~Hz}, 4 \mathrm{H}), 2.77$ (quintet, $J=$ $6.5 \mathrm{~Hz}, 4 \mathrm{H}), 1.34$ (s, 36H), 1.18 (d, J=6.6 Hz, 24H), $0.090(\mathrm{~s}, 9 \mathrm{H})$; MALDI-MS obsd 2220.0 [(M+ H $\left.)^{+}\right]$, calcd $2219.8771(\mathrm{M}=$ $\left.\mathrm{C}_{149} \mathrm{H}_{126} \mathrm{~N}_{6} \mathrm{O}_{8} \mathrm{SiZn}\right)$. 
5,15-Bis[2-(3,4-( $N$-(2,6-diisopropylphenyl)iminodicarbonyl)1,6-bis(4-tert-butylphenoxy)perylen-9-yl)ethynyl]-10-(4ethynylphenyl)-20-phenylporphyrin (T-Ph-H)

A solution of T-Ph $(7.0 \mathrm{mg}, 3.2 \mu \mathrm{mol})$ in toluene $(3.0 \mathrm{~mL})$ and methanol $(3.0 \mathrm{~mL})$ was treated with $\mathrm{K}_{2} \mathrm{CO}_{3}(44 \mathrm{mg}, 0.32 \mathrm{mmol})$ and stirred at room temperature for $3 \mathrm{~h}$. The reaction was quenched by the addition of water. The mixture was extracted with $\mathrm{CH}_{2} \mathrm{Cl}_{2}$. The organic extract was washed with brine, dried, and concentrated to afford a black solid (6.7 mg, quant.): ${ }^{1} \mathrm{H}$ NMR $\left(\mathrm{CDCl}_{3}, 300 \mathrm{MHz}\right): \delta 9.73(\mathrm{~d}, J=5.1 \mathrm{~Hz}, 4 \mathrm{H}) ; 9.27$ (d, $J=$ $7.2 \mathrm{~Hz}, 2 \mathrm{H}), 9.21(\mathrm{~d}, J=7.8 \mathrm{~Hz}, 2 \mathrm{H}), 9.02(\mathrm{~d}, J=8.1 \mathrm{~Hz}, 2 \mathrm{H}), 8.84$ $(\mathrm{d}, J=5.1 \mathrm{~Hz}, 2 \mathrm{H}), 8.80(\mathrm{~d}, J=5.1 \mathrm{~Hz}, 2 \mathrm{H}), 8.34(\mathrm{~s}, 2 \mathrm{H}), 8.28$ (s, $2 \mathrm{H}), 8.10-8.20(\mathrm{~m}, 4 \mathrm{H}), 7.91(\mathrm{~d}, J=7.8 \mathrm{~Hz}, 2 \mathrm{H}), 7.79(\mathrm{~m}, 3 \mathrm{H})$, $7.67(\mathrm{t}, J=7.8 \mathrm{~Hz}, 2 \mathrm{H}), 7.39-7.49(\mathrm{~m}, 12 \mathrm{H}), 7.32-7.00(\mathrm{~m}, 12 \mathrm{H})$, $3.36(\mathrm{~s}, 1 \mathrm{H}), 2.77$ (quintet, $J=6.6 \mathrm{~Hz}, 4 \mathrm{H}), 1.34(\mathrm{~s}, 36 \mathrm{H}), 1.18(\mathrm{~d}, J$ $=6.6 \mathrm{~Hz}, 24 \mathrm{H}),-1.88(\mathrm{~s}, 2 \mathrm{H})$; MALDI-MS obsd $2085.7\left[(\mathrm{M}+\mathrm{H})^{+}\right]$, calcd $2084.9168\left(\mathrm{M}=\mathrm{C}_{146} \mathrm{H}_{120} \mathrm{~N}_{6} \mathrm{O}_{8}\right) ; \lambda_{\text {abs }}$ (toluene) 429, 476, $537,638,726 \mathrm{~nm}$.

5,15-Bis[2-(3,4-( $N$-(2,6-diisopropylphenyl)iminodicarbonyl)1,6-bis(4-tert-butylphenoxy)perylen-9-yl)ethynyl]-10-[4-(2-(4(9,10-( $N$-(2,6-diisopropylphenyl)iminodicarbonyl)perylene3,4-dicarboximido)phenyl)ethynyl)phenyl]-20phenylporphyrin (T-PDI)

Following the general procedure for Pd-catalyzed coupling reactions described above, a mixture of the triad T-Ph-H (34 mg, $16 \mu \mathrm{mol})$, iodophenyl-perylene-diimide $7(12 \mathrm{mg}, 16 \mu \mathrm{mol})$, $\mathrm{Pd}_{2}(\mathrm{dba})_{3}(2.2 \mathrm{mg}, 2.4 \mu \mathrm{mol})$, and $\mathrm{P}(o \text {-tol })_{3}(5.4 \mathrm{mg}, 18 \mu \mathrm{mol})$ in toluene/TEA $(5: 1,4.0 \mathrm{~mL})$ was stirred at $60{ }^{\circ} \mathrm{C}$ for $4 \mathrm{~h}$. The mixture was allowed to cool to room temperature and then was chromatographed according to the three-chromatography method to afford a black solid (17 mg, 40\%): ${ }^{1} \mathrm{H}$ NMR $\left(\mathrm{CDCl}_{3}\right.$, $400 \mathrm{MHz}) \delta 9.78(\mathrm{~d}, J=5.1 \mathrm{~Hz}, 4 \mathrm{H}) ; 9.30(\mathrm{~d}, J=7.2 \mathrm{~Hz}, 2 \mathrm{H}), 9.20$ $(\mathrm{d}, J=7.8 \mathrm{~Hz}, 2 \mathrm{H}), 9.01(\mathrm{~d}, J=8.1 \mathrm{~Hz}, 2 \mathrm{H}), 8.88(\mathrm{~d}, J=5.1 \mathrm{~Hz}$, $2 \mathrm{H}), 8.80-8.60(\mathrm{~m}, 10 \mathrm{H}), 8.34(\mathrm{~s}, 2 \mathrm{H}), 8.28(\mathrm{~s}, 2 \mathrm{H}), 8.10-8.20(\mathrm{~m}$, $4 \mathrm{H}), 7.94-7.90(\mathrm{~m}, 4 \mathrm{H}), 7.79(\mathrm{~m}, 3 \mathrm{H}), 7.67(\mathrm{t}, J=7.8 \mathrm{~Hz}, 2 \mathrm{H})$, 7.30-7.52 (m, 19H), 7.15-7.05 (m, 10H), 2.80-2.77 (m, 6H), 1.34 (s, 36H), 1.20-1.18 (m, 36H), -1.95 (s, 2H); MALDI-MS obsd $2711.0\left[(\mathrm{M}+\mathrm{H})^{+}\right]$, calcd 2709.1217 $\left(\mathrm{M}=\mathrm{C}_{188} \mathrm{H}_{148} \mathrm{~N}_{8} \mathrm{O}_{12}\right) ; \lambda_{\text {abs }}$ (toluene) 430, 463, 492, 530, 639, $727 \mathrm{~nm}$.

5,15-Bis[2-(3,4-( $N$-(2,6-diisopropylphenyl)iminodicarbonyl)1,6-bis(4-tert-butylphenoxy)perylen-9-yl)ethynyl]-10-[4-(2-(4(9,10-( $N$-(2,6-diisopropylphenyl)iminodicarbonyl)perylene3,4-dicarboximido)phenyl)ethynyl)phenyl]-20-

phenylporphyrinatozinc(II) (ZnT-PDI)

A solution of T-PDI $(0.020 \mathrm{~g}, 7.4 \mu \mathrm{mol}, 1.0$ equiv. $)$ in $\mathrm{CH}_{2} \mathrm{Cl}_{2} /$ $\mathrm{CH}_{3} \mathrm{OH}(2: 1,2.2 \mathrm{~mL})$ was treated with $\mathrm{Zn}(\mathrm{OAc})_{2} \cdot 2 \mathrm{H}_{2} \mathrm{O}(32 \mathrm{mg}$, $0.15 \mathrm{mmol}, 20$ equiv.) at room temperature for $22 \mathrm{~h}$, then washed with water. The organic layer was dried, concentrated, and chromatographed by SEC (HPLC-grade toluene) followed by silica gel $\left(\mathrm{CH}_{2} \mathrm{Cl}_{2} / \mathrm{CH}_{3} \mathrm{OH}=1: 1\right.$ to $\left.9: 1\right)$ to afford a black solid $(0.020 \mathrm{~g}$, quant.): ${ }^{1} \mathrm{H} \mathrm{NMR}\left(\mathrm{CDCl}_{3}, 400 \mathrm{MHz}\right) \delta 9.78(\mathrm{~d}, J=5.1 \mathrm{~Hz}, 4 \mathrm{H}) ; 9.30$ $(\mathrm{d}, J=7.2 \mathrm{~Hz}, 2 \mathrm{H}), 9.20(\mathrm{~d}, J=7.8 \mathrm{~Hz}, 2 \mathrm{H}), 9.01(\mathrm{~d}, J=8.1 \mathrm{~Hz}, 2 \mathrm{H})$, $8.88(\mathrm{~d}, J=5.1 \mathrm{~Hz}, 2 \mathrm{H}), 8.80-8.60(\mathrm{~m}, 10 \mathrm{H}), 8.34$ (s, 2H), 8.28 (s,
2H), 8.10-8.20 (m, 4H), 7.94-7.90 (m, 4H), $7.79(\mathrm{~m}, 3 \mathrm{H}), 7.67(\mathrm{t}, J=$ $7.8 \mathrm{~Hz}, 2 \mathrm{H}), 7.30-7.52$ (m, 19H), 7.15-7.05 (m, 10H), 2.80-2.77 (m, $6 \mathrm{H}), 1.34$ (s, 36H), 1.20-1.18 (m, 36H); MALDI-MS obsd 2772.9 [(M $\left.+\mathrm{H})^{+}\right]$, calcd $2771.0352\left(\mathrm{M}=\mathrm{C}_{188} \mathrm{H}_{146} \mathrm{~N}_{8} \mathrm{O}_{12} \mathrm{Zn}\right)$.

5,15-Bis[2-(3,4-( $N$-(2,6-diisopropylphenyl)iminodicarbonyl)1,6-bis(4-tert-butylphenoxy)perylen-9-yl)ethynyl]-10-[4-(2-(4(10-mesityl-18,18-dimethylchlorin-5-yl)phenyl)ethynyl) phenyl]-20-phenylporphyrin (C-T)

Following the general procedure for Pd-catalyzed coupling reactions described above, a mixture of the triad T-Ph-H (33 mg, $16 \mu \mathrm{mol})$, iodophenyl-chlorin 5 (11 mg, $16 \mu \mathrm{mol}), \mathrm{Pd}_{2}(\mathrm{dba})_{3}$ (2.2 mg, $2.4 \mu \mathrm{mol})$, and $\mathrm{P}(o \text {-tol })_{3}(5.4 \mathrm{mg}, 18 \mu \mathrm{mol})$ in toluene/ TEA $(5: 1,4.0 \mathrm{~mL})$ was stirred at $60{ }^{\circ} \mathrm{C}$ for $3 \mathrm{~h}$. The mixture was allowed to cool to room temperature and then was chromatographed according to the three-chromatography method to afford a black solid (10 mg, 24\%): ${ }^{1} \mathrm{H} \mathrm{NMR}\left(\mathrm{CDCl}_{3}, 400 \mathrm{MHz}\right)$ $\delta$ 9.79-9.77 (m, 2H), 9.53-9.44 (m, 4H), $9.10(\mathrm{~d}, J=7.6 \mathrm{~Hz}, 2 \mathrm{H})$, $8.98(\mathrm{~s}, 1 \mathrm{H}), 8.92-8.85(\mathrm{~m}, 4 \mathrm{H}), 8.78(\mathrm{~d}, J=4.0 \mathrm{~Hz}, 1 \mathrm{H}), 8.63(\mathrm{~d}, J$ $=4.8 \mathrm{~Hz}, 1 \mathrm{H}),-1.89(\mathrm{~s}, 2 \mathrm{H}), 8.54(\mathrm{~d}, J=4.4 \mathrm{~Hz}, 1 \mathrm{H}), 8.50(\mathrm{~m}$, $1 \mathrm{H}), 8.42(\mathrm{~d}, J=4.4 \mathrm{~Hz}, 1 \mathrm{H}), 8.36(\mathrm{~s}, 1 \mathrm{H}), 8.35(\mathrm{~s}, 1 \mathrm{H}), 8.32(\mathrm{~d}, J=$ $8.0 \mathrm{~Hz}, 2 \mathrm{H}), 8.19-8.21(\mathrm{~m}, 3 \mathrm{H}), 8.08$ (d, $J=8.4 \mathrm{~Hz}, 1 \mathrm{H}), 8.01$ (d, $J$ $=8.4 \mathrm{~Hz}, 2 \mathrm{H}), 7.87-7.77(\mathrm{~m}, 5 \mathrm{H}), 7.52-7.42(\mathrm{~m}, 11 \mathrm{H}), 7.31(\mathrm{~d}, J=$ $8.0 \mathrm{~Hz}, 6 \mathrm{H}), 7.13-7.10(\mathrm{~m}, 8 \mathrm{H}), 4.65(\mathrm{~s}, 2 \mathrm{H}), 2.74$ (quintet, $J=$ $6.8 \mathrm{~Hz}, 6 \mathrm{H}), 2.62(\mathrm{~s}, 3 \mathrm{H}), 2.10(\mathrm{~s}, 6 \mathrm{H}), 1.89(\mathrm{~s}, 6 \mathrm{H}), 1.34(\mathrm{~s}, 36 \mathrm{H})$, $1.16(\mathrm{~d}, J=6.8 \mathrm{~Hz}, 36 \mathrm{H}),-1.81(\mathrm{~s}, 2 \mathrm{H}),-1.90(\mathrm{~s}, 2 \mathrm{H})$; MALDI-MS obsd 2618.6 $\left[(\mathrm{M}+\mathrm{H})^{+}\right]$, calcd $2617.1795\left(\mathrm{M}=\mathrm{C}_{183} \mathrm{H}_{152} \mathrm{~N}_{10} \mathrm{O}_{8}\right)$; $\lambda_{\text {abs }}$ (toluene) 416, 477, 511, 537, 641, $728 \mathrm{~nm}$.

\section{5,15-Bis(2-phenylethynyl)-10-[4-(2-trimethylsilylethynyl)} phenyl]-20-[4-(2-triisopropylsilylethynyl)phenyl]porphyrin (PTMS/TIPS)

Following the general procedure for Pd-catalyzed coupling reactions described above, a mixture of porphyrin $4-\mathbf{B r}_{2} / \mathbf{T M S}$ / TIPS (47 mg, $52 \mu \mathrm{mol}, 1.0$ equiv.), phenylacetylene (13 mg, $0.13 \mathrm{mmol}, 2.5$ equiv.), $\mathrm{Pd}_{2}(\mathrm{dba})_{3} \cdot \mathrm{CHCl}_{3}(8.1 \mathrm{mg}, 7.9 \mu \mathrm{mol}, 0.15$ equiv. $)$, and $\mathrm{P}(\mathrm{o} \text {-tol })_{3}(19 \mathrm{mg}, 62 \mu \mathrm{mol}, 1.2$ equiv. $)$ in toluene/TEA $(5: 1,10.2 \mathrm{~mL})$ was stirred at $60{ }^{\circ} \mathrm{C}$ for $2 \mathrm{~h}$. The mixture was then washed with water. The organic layer was dried, concentrated, and chromatographed (silica gel, hexanes $/ \mathrm{CH}_{2} \mathrm{Cl}_{2}, 2: 1$ ) to afford a blue solid (38 mg, 78\%): TLC (silica, hexanes $/ \mathrm{CH}_{2} \mathrm{Cl}_{2}$, $3: 2) R_{\mathrm{f}}=0.54 ;{ }^{1} \mathrm{H} \mathrm{NMR}\left(\mathrm{CDCl}_{3}, 300 \mathrm{MHz}\right) \delta 9.65(\mathrm{~d}, J=4.7 \mathrm{~Hz}$, $4 \mathrm{H}), 8.78(\mathrm{dd}, J=9.3,4.8 \mathrm{~Hz}, 4 \mathrm{H}), 8.12(\mathrm{~d}, J=8.0 \mathrm{~Hz}, 4 \mathrm{H}), 8.02$ $(\mathrm{d}, J=6.6 \mathrm{~Hz}, 4 \mathrm{H}), 8.00-7.88(\mathrm{~m}, 4 \mathrm{H}), 7.60-7.50(\mathrm{~m}, 6 \mathrm{H}), 1.27-$ $1.25(\mathrm{~m}, 21 \mathrm{H}), 0.40(\mathrm{~s}, 9 \mathrm{H}),-2.09(\mathrm{~s}, 2 \mathrm{H})$; ESI-MS obsd 939.4105 $\left[(\mathrm{M}+\mathrm{H})^{+}\right]$, calcd $938.4200\left(\mathrm{M}=\mathrm{C}_{64} \mathrm{H}_{58} \mathrm{~N}_{4} \mathrm{Si}_{2}\right)$.

5-[4-(2-(4-(9,10-(N-(2,6-Diisopropylphenyl)iminodicarbonyl) perylene-3,4-dicarboximido)phenyl)ethynyl)phenyl]-10,20bis(2-phenylethynyl)-15-[4-(2-triisopropylsilylethynyl)phenyl] porphyrin (9)

A mixture of P-TMS/TIPS (10 $\mathrm{mg}, 0.011 \mathrm{mmol}, 1.0$ equiv.) and $\mathrm{K}_{2} \mathrm{CO}_{3}$ (0.15 g, $1.1 \mathrm{mmol}, 100$ equiv.) in $\mathrm{THF} / \mathrm{CH}_{3} \mathrm{OH}(1: 1,10$ $\mathrm{mL}$ ) was stirred at room temperature for $30 \mathrm{~min}$. The reaction was then quenched by the addition of $2 \mathrm{M} \mathrm{HCl}$ solution $(10 \mathrm{~mL})$. The mixture was extracted with $\mathrm{CH}_{2} \mathrm{Cl}_{2}$. The organic extract was 
dried and concentrated to dryness. Following the general procedure for Pd-catalyzed coupling reactions described above, a mixture of the resulting sample, iodophenyl-perylene-diimide 7 (8.3 mg, $0.011 \mathrm{mmol}, 1.0$ equiv.), $\mathrm{Pd}_{2}(\mathrm{dba})_{3} \cdot \mathrm{CHCl}_{3}(1.7 \mathrm{mg}, 1.6$ $\mu \mathrm{mol}, 0.15$ equiv. $)$, and $\mathrm{P}(o \text {-tol })_{3}(4.0 \mathrm{mg}, 0.013 \mathrm{mmol}, 1.2$ equiv. $)$ in toluene/TEA $(5: 1,2.4 \mathrm{~mL})$ was stirred at $60{ }^{\circ} \mathrm{C}$ for $2 \mathrm{~h}$. The mixture was then allowed to cool to room temperature and passed through a pad of silica gel $\left(\mathrm{CH}_{2} \mathrm{Cl}_{2}\right)$. The eluate was concentrated and chromatographed (silica gel, $\mathrm{CH}_{2} \mathrm{Cl}_{2}$ ) to afford a green solid (7.9 mg, 49\%): TLC (silica, $\left.\mathrm{CH}_{2} \mathrm{Cl}_{2}\right) R_{\mathrm{f}}=$

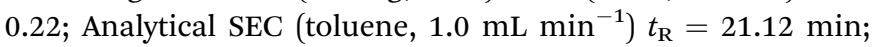
MALDI-MS obsd $1491\left(\mathrm{M}^{+}\right)$, calcd $1490.5854(\mathrm{M}=$ $\mathrm{C}_{103} \mathrm{H}_{78} \mathrm{~N}_{6} \mathrm{O}_{4} \mathrm{Si}$ ); $\lambda_{\text {abs }}$ (toluene) 445, 491, 528, 600, $692 \mathrm{~nm}$. The compound was not characterized by NMR spectroscopy due to limited solubility in organic solvents.

5-[4-(2-(4-(9,10-(N-(2,6-Diisopropylphenyl)iminodicarbonyl) perylene-3,4-dicarboximido)phenyl)ethynyl)phenyl]-15-[4-(2(4-(10-mesityl-18,18-dimethylchlorin-5-yl)phenyl)ethynyl) phenyl]-10,20-bis(2-phenylethynyl)porphyrin (C-P-PDI)

A solution of 9 (6.5 mg, $0.0044 \mathrm{mmol}, 1.0$ equiv. $)$ in THF $(2.2 \mathrm{~mL})$ was treated with $1 \mathrm{M}$ TBAF solution in $\mathrm{THF}(8.7 \mu \mathrm{L}$, 0.0087 mmol, 2.0 equiv.) at room temperature for $2 \mathrm{~h}$, then treated with water. The mixture was extracted with $\mathrm{CH}_{2} \mathrm{Cl}_{2}$. The organic extract was dried and concentrated to dryness. Following the general procedure for Pd-catalyzed coupling reactions described above, a mixture of the resulting sample, iodophenyl-chlorin 5 (2.9 mg, $0.044 \mathrm{mmol}, 1.0$ equiv.), $\operatorname{Pd}_{2}(-$ $\mathrm{dba})_{3} \cdot \mathrm{CHCl}_{3}(1.4 \mathrm{mg}, 0.00132 \mathrm{mmol}, 0.30$ equiv. $)$, and $\mathrm{P}(o \text {-tol })_{3}$ (1.6 mg, $0.0053 \mathrm{mmol}, 1.2$ equiv.) in toluene/TEA $(5: 1,1.2 \mathrm{~mL})$ was stirred at $60^{\circ} \mathrm{C}$ for $2 \mathrm{~h}$. The mixture was then allowed to cool to room temperature. Purification according to the threechromatography method afforded a green solid (1.4 mg, 17\%): TLC (silica, $\left.\mathrm{CH}_{2} \mathrm{Cl}_{2} / \mathrm{CH}_{3} \mathrm{OH}=99: 1\right) R_{\mathrm{f}}=0.52 ;{ }^{1} \mathrm{H}$ NMR (THF$\left.d_{8}, 400 \mathrm{MHz}\right) \delta 9.68(\mathrm{dd}, J=11.8,4.3 \mathrm{~Hz}, 4 \mathrm{H}), 8.87-8.86(\mathrm{~m}, 4 \mathrm{H})$, $8.68-8.64(\mathrm{~m}, 2 \mathrm{H}), 8.58(\mathrm{~s}, 2 \mathrm{H}), 8.54(\mathrm{~d}, J=4.5 \mathrm{~Hz}, 1 \mathrm{H}), 8.40-8.32$ $(\mathrm{m}, 4 \mathrm{H}), 8.29-8.27(\mathrm{~m}, 5 \mathrm{H}), 8.21-7.98(\mathrm{~m}, 15 \mathrm{H}), 7.71-7.51(\mathrm{~m}$, $12 \mathrm{H}), 7.24(\mathrm{~s}, 2 \mathrm{H}), 4.56(\mathrm{~s}, 2 \mathrm{H}), 3.10-3.02(\mathrm{~m}, 2 \mathrm{H}), 2.05(\mathrm{~s}, 9 \mathrm{H})$, 1.89 (s, 6H), 1.30-1.29 (m, 16H), -1.82 (s, 2H), -1.88 (s, 2H); MALDI-MS obsd 1867.6 [(M $\left.+\mathrm{H})^{+}\right]$, calcd $1866.7143(\mathrm{M}=$ $\mathrm{C}_{131} \mathrm{H}_{90} \mathrm{~N}_{10} \mathrm{O}_{4}$ ); $\lambda_{\text {abs }}$ (toluene) 418, 446, 528, 600, 642, $692 \mathrm{~nm}$.

5-[4-(2-(4-(9,10-(N-(2,6-Diisopropylphenyl)iminodicarbonyl) perylene-3,4-dicarboximido)phenyl)ethynyl)phenyl]-15-[4-(2(4-(10-mesityl-18,18-dimethylchlorinatozinc(II)-5-yl)phenyl) ethynyl)phenyl]-10,20-bis(2-phenylethynyl) porphyrinatozinc(II) (ZnC-ZnP-PDI)

A solution of C-P-PDI (1.0 mg, $0.54 \mu \mathrm{mol}, 1.0$ equiv.) in THF (1.0 $\mathrm{mL}$ ) was treated with $\mathrm{Zn}(\mathrm{OAc})_{2}(2.3 \mathrm{mg}, 0.011 \mathrm{mmol}, 20$ equiv.) at room temperature for $18 \mathrm{~h}$. The sample was treated with water and extracted with $\mathrm{CH}_{2} \mathrm{Cl}_{2}$. The organic extract was dried and concentrated to afford a green solid (1.0 mg, quant.): TLC (silica, $\mathrm{CH}_{2} \mathrm{Cl}_{2} / \mathrm{CH}_{3} \mathrm{OH}=99$ : 1) $R_{\mathrm{f}}=0.44 ;{ }^{1} \mathrm{H}$ NMR (THF- $d_{8}, 400$ $\mathrm{MHz}) \delta 9.65(\mathrm{dd}, J=11.8,4.3 \mathrm{~Hz}, 4 \mathrm{H}), 8.87-8.86(\mathrm{~m}, 4 \mathrm{H}), 8.68-$ $8.64(\mathrm{~m}, 2 \mathrm{H}), 8.58(\mathrm{~s}, 2 \mathrm{H}), 8.54(\mathrm{~d}, J=4.5 \mathrm{~Hz}, 1 \mathrm{H}), 8.40-8.36(\mathrm{~m}$, $4 \mathrm{H}), 8.29-8.27$ (m, 5H), 8.21-7.98 (m, 15H), 7.71-7.41 (m, 12H), $7.24(\mathrm{~s}, 2 \mathrm{H}), 4.53$ (s, 2H), 3.06-3.02 (m, 2H), 2.05 (s, 9H), 1.89 (s, $6 \mathrm{H}), 1.30-1.29(\mathrm{~m}, 16 \mathrm{H})$; MALDI-MS obsd $1991.5\left[(\mathrm{M}+\mathrm{H})^{+}\right]$, calcd $1990.5\left(\mathrm{M}=\mathrm{C}_{131} \mathrm{H}_{86} \mathrm{~N}_{10} \mathrm{O}_{4} \mathrm{Zn}_{2}\right) ; \lambda_{\text {abs }}$ (toluene) 418, 446, 528, 600, 642, $692 \mathrm{~nm}$.

5,15-Bis[2-(3,4-( $N$-(2,6-diisopropylphenyl)iminodicarbonyl)1,6-bis(4-tert-butylphenoxy)perylen-9-yl)ethynyl]-10-[4-(2trimethylsilylethynyl)phenyl]-20-[4-(2-triisopropylsilylethynyl) phenyl]porphyrin (T-TMS/TIPS)

Following the general procedure for Pd-catalyzed coupling reactions described above, a mixture of dibromoporphyrin 4$\mathbf{B r}_{2} /$ TMS/TIPS (14 mg, $16 \mu \mathrm{mol}$ ), ethynylperylene-monoimide 8 $(26 \mathrm{mg}, 32 \mu \mathrm{mol}), \mathrm{Pd}_{2}(\mathrm{dba})_{3}(4.4 \mathrm{mg}, 4.8 \mu \mathrm{mol})$, and $\mathrm{P}(o \text {-tol })_{3}$ $(12 \mathrm{mg}, 38 \mu \mathrm{mol})$ in toluene/TEA $(5: 1,6.4 \mathrm{~mL})$ was stirred at $60{ }^{\circ} \mathrm{C}$ for $4 \mathrm{~h}$. The mixture was allowed to cool to room temperature and then chromatographed according to the threechromatography method to afford a black solid (28 $\mathrm{mg}, 76 \%)$ : ${ }^{1} \mathrm{H} \mathrm{NMR}\left(\mathrm{CDCl}_{3}, 300 \mathrm{MHz}\right), \delta 9.78(\mathrm{~d}, J=4.8 \mathrm{~Hz}, 4 \mathrm{H}), 9.48(\mathrm{dd}, J$ $=7.2,3.9 \mathrm{~Hz}, 2 \mathrm{H}), 9.11(\mathrm{~d}, J=7.8 \mathrm{~Hz}, 2 \mathrm{H}), 8.86(\mathrm{dd}, J=7.8$, $4.5 \mathrm{~Hz}, 4 \mathrm{H}), 8.37(\mathrm{~s}, 2 \mathrm{H}), 8.36(\mathrm{~s}, 2 \mathrm{H}), 8.34(\mathrm{~d}, J=8.4 \mathrm{~Hz}, 2 \mathrm{H})$, $8.15(\mathrm{~d}, J=7.8 \mathrm{~Hz}, 4 \mathrm{H}), 7.92(\mathrm{dd}, J=8.4,3.0 \mathrm{~Hz}, 4 \mathrm{H}), 7.86(\mathrm{~d}, J=$ $8.1 \mathrm{~Hz}, 2 \mathrm{H}), 7.73(\mathrm{t}, J=5.7 \mathrm{~Hz}, 2 \mathrm{H}), 7.40-7.43(\mathrm{~m}, 10 \mathrm{H}), 7.32(\mathrm{~s}$, $2 \mathrm{H}), 7.30(\mathrm{~s}, 2 \mathrm{H}), 7.12(\mathrm{dd}, J=9.0,2.1 \mathrm{~Hz}, 8 \mathrm{H}), 2.75$ (hept, $J=$ $6.9 \mathrm{~Hz}, 4 \mathrm{H}), 2.04$ (hept, $J=6.9 \mathrm{~Hz}, 3 \mathrm{H}), 1.36(\mathrm{~d}, J=1.8 \mathrm{~Hz}, 36 \mathrm{H})$, $1.17(\mathrm{~d}, J=6.6 \mathrm{~Hz}, 24 \mathrm{H}), 0.99$ (d, $J=6.9 \mathrm{~Hz}, 18 \mathrm{H}), 0.40(\mathrm{~s}, 9 \mathrm{H})$, -1.81 (s, 2H); MALDI-MS obsd 2337.2 [ $\left.\mathrm{M}^{+}\right]$, calcd 2337.0897 (M $\left.=\mathrm{C}_{160} \mathrm{H}_{148} \mathrm{~N}_{6} \mathrm{O}_{8} \mathrm{Si}_{2}\right) ; \lambda_{\text {abs }}\left(\mathrm{CH}_{2} \mathrm{Cl}_{2}\right) 423,471,531,636,725 \mathrm{~nm}$.

\section{5,15-Bis[2-(3,4-( $N$-(2,6-diisopropylphenyl)iminodicarbonyl)-} 1,6-bis(4-tert-butylphenoxy)perylen-9-yl)ethynyl]-10-[4-(2-(4(9,10-( $N$-(2,6-diisopropylphenyl)iminodicarbonyl)perylene3,4-dicarboximido)phenyl)ethynyl)phenyl]-20-[4-(2triisopropylsilylethynyl)phenyl]porphyrin (T-H/PDI)

A solution of T-TMS/TIPS $(28 \mathrm{mg}, 12 \mu \mathrm{mol})$ in THF/MeOH $(3: 1$, $12 \mathrm{~mL}$ ) was treated with $\mathrm{K}_{2} \mathrm{CO}_{3}(11 \mathrm{mg}, 80 \mu \mathrm{mol})$ at room temperature for $1 \mathrm{~h}$. The reaction was quenched by the addition of water. The mixture was extracted with $\mathrm{CH}_{2} \mathrm{Cl}_{2}$. The organic extract was washed with brine, dried, and concentrated to dryness. Following the general procedure for Pd-catalyzed coupling reactions described above, a mixture of the resulting solid, iodophenyl-perylene-diimide 7 (11 $\mathrm{mg}, 14 \mu \mathrm{mol})$, $\mathrm{Pd}_{2}(\mathrm{dba})_{3}(1.6 \mathrm{mg}, 1.8 \mu \mathrm{mol})$, and $\mathrm{P}(o \text {-tol })_{3}(4.3 \mathrm{mg}, 14 \mu \mathrm{mol})$ in toluene/TEA $(5: 1,4.8 \mathrm{~mL})$ was stirred at $60{ }^{\circ} \mathrm{C}$ for $4 \mathrm{~h}$. The mixture was washed with water and extracted with $\mathrm{CH}_{2} \mathrm{Cl}_{2}$. The organic extract was washed with brine, dried, and concentrated to dryness. A solution of the resulting solid in THF $(2.0 \mathrm{~mL})$ was treated dropwise with 1.0 M TBAF solution in THF $(7.8 \mu \mathrm{L}, 7.8$ $\mu \mathrm{mol})$ and stirred for $1 \mathrm{~h}$ at room temperature. The reaction was quenched by the addition of saturated aqueous $\mathrm{NaHCO}_{3}$ solution. The mixture was extracted with ethyl acetate. The organic extract was washed with brine, dried, concentrated, and chromatographed according to the three-chromatography method to afford a black solid (11 mg, 40\%): MALDI-MS obsd 2889.7 $\left(\mathrm{M}^{+}\right)$, calcd 2889.2551 ( $\left.\mathrm{M}=\mathrm{C}_{199} \mathrm{H}_{168} \mathrm{~N}_{8} \mathrm{O}_{12} \mathrm{Si}\right) ; \lambda_{\text {abs }}$ (toluene) 431, $459,491,530,641,730 \mathrm{~nm}$. The purity of the sample was 
estimated to be $>95 \%$ according to analytical SEC. The sample was used directly in the next step without further characterization.

5,15-Bis[2-(3,4-( $N$-(2,6-diisopropylphenyl)iminodicarbonyl)1,6-bis(4-tert-butylphenoxy)perylen-9-yl)ethynyl]-10-[4-(2-(4(9,10-( $N$-(2,6-diisopropylphenyl)iminodicarbonyl)perylene3,4-dicarboximido)phenyl)ethynyl)phenyl]-20-[4-(2-(4-(10mesityl-18,18-dimethylchlorin-5-yl)phenyl)ethynyl)phenyl] porphyrin (C-T-PDI)

Following the general procedure for Pd-catalyzed coupling reactions described above, a solution of T-H/PDI $(11 \mathrm{mg}, 4.0$ $\mu \mathrm{mol})$, iodophenyl-chlorin $5(4.0 \mathrm{mg}, 6.0 \mu \mathrm{mol}), \mathrm{Pd}_{2}(\mathrm{dba})_{3}$ $(1.0 \mathrm{mg}, 1.1 \mu \mathrm{mol})$, and $\mathrm{P}(o \text {-tol })_{3}(1.5 \mathrm{mg}, 4.8 \mu \mathrm{mol})$ in toluene/ TEA $(5: 1,1.6 \mathrm{~mL})$ was stirred at $60{ }^{\circ} \mathrm{C}$ for $18 \mathrm{~h}$. The mixture was chromatographed according to the three-chromatography method to afford a black solid (3.5 mg, 27\%): ${ }^{1} \mathrm{H}$ NMR $\left(\mathrm{CDCl}_{3}, 700 \mathrm{MHz}\right) \delta 9.77-9.73(\mathrm{~m}, 4 \mathrm{H}), 9.37-9.11(\mathrm{~m}, 4 \mathrm{H}), 8.93-$ $8.64(\mathrm{~m}, 12 \mathrm{H}), 8.55-8.44(\mathrm{~m}, 6 \mathrm{H}), 8.42-8.32(\mathrm{~m}, 4 \mathrm{H}), 8.25-7.91$ $(\mathrm{m}, 12 \mathrm{H}), 7.82(\mathrm{~d}, J=6.2 \mathrm{~Hz}, 4 \mathrm{H}), 7.52(\mathrm{~d}, J=7.7 \mathrm{~Hz}, 3 \mathrm{H}), 7.43-$ 7.49 (m, 16H), 7.35-7.43 (m, 6H), 7.32 (d, $J=8.2 \mathrm{~Hz}, 4 \mathrm{H}),-1.91$ (br, 1H), 7.04-7.13 (m, 6H), 4.66 (s, 2H), 2.76 (pent, $J=7.1 \mathrm{~Hz}$, $6 \mathrm{H}), 2.64$ (s, 3H), 2.01-2.09 (m, 6H), 1.36-1.38 (m, 36H), 1.18 (d, $J=5.8 \mathrm{~Hz}, 42 \mathrm{H}),-1.73$ (br, $1 \mathrm{H}),-1.79$ (br, $1 \mathrm{H}),-1.84$ (br, 2H); MALDI-MS obsd $3265.8\left[\mathrm{M}^{+}\right]$, calcd $3265.3844 \quad(\mathrm{M}=$ $\mathrm{C}_{227} \mathrm{H}_{180} \mathrm{~N}_{12} \mathrm{O}_{12}$ ); $\lambda_{\text {abs }}$ (toluene) 418, 494, 530, 641, $742 \mathrm{~nm}$.

\section{Photophysical properties}

Static absorption (Shimadzu UV-1800) and emission (Horiba Nanolog) and other measurements were performed on dilute $(\mu \mathrm{M})$, Ar-purged solutions in toluene at room temperature. Fluorescence quantum yields $\left(\Phi_{\mathrm{f}}\right)$ utilized samples with $A \leq 0.1$ at the excitation wavelength and were obtained by absolute measurements (Horiba QuantiPhi). Values for several arrays were also obtained by relative $\Phi_{\mathrm{f}}$ measurements using mesotetraphenylporphyrin in non-degassed toluene $\left(\Phi_{\mathrm{f}}=0.070\right)^{30}$ as a standard and gave the same values as the absolute measurements within experimental uncertainty $( \pm 5 \%$ of the reported value).

\section{Conflicts of interest}

The authors declare no competing financial interests.

\section{Acknowledgements}

This work was supported by a grant from the Chemical Sciences, Geosciences and Biosciences Division, Office of Basic Energy Sciences, of the U. S. Department of Energy (DE-FG0205ER15661). All mass spectrometry measurements were carried out in the Molecular Education, Technology, and Research Innovation Center (METRIC) at NC State University.

\section{References}

1 A. A. Krasnovsky, The Fragments of the Photosynthetic Electron Transfer Chain in Model Systems,, Biophys. J., 1972, 12, 749-763.

2 G. Porter and M. D. Archer, In Vitro Photosynthesis, Interdiscip. Sci. Rev., 1976, 1, 119-143.

3 D. Mauzerall, Electron-Transfer Reactions and Photoexcited Porphyrins, Brookhaven Symp. Biol., 1977, 28, 64-73.

4 D. Mauzerall, Photoinduced Electron Transfer at the WaterLipid Bilayer Membrane, in Light-Induced Charge Separation in Biology and Chemistry, ed. H. Gerischer and J. J. Katz, Berlin: Dahlem Konferenzen, Verlag-Chemie, Weinheim, 1979, vol. 12, pp. 241-257.

5 A. Harriman and J. Barber, Photosynthetic Water-Splitting Process and Artificial Chemical Systems, in Photosynthesis in Relation to Model Systems. Topics in Photosynthesis, ed. J. Barber, Elsevier/North-Holland Biomedical Press, NY, 1979, vol. 3, ch. 8, pp. 243-280.

6 M. Calvin, Synthetic Chloroplasts, Energy Res., 1979, 3, 7387.

7 P. Cuendet and M. Grätzel, Artificial Photosynthetic Systems, Experientia, 1982, 38, 223-228.

8 S. G. Boxer, Model Reactions in Photosynthesis, Biochim. Biophys. Acta, 1983, 726, 265-292.

9 H. T. Tien, Planar Bilayer Lipid Membranes, Prog. Surf. Sci., 1985, 19, 169-274.

10 M. R. Wasielewski and M. P. Niemczyk, Distance-Dependent Rates of Photoinduced Charge Separation and Dark Charge Recombination in Fixed-Distance Porphyrin-Quinone Molecules, in Porphyrins - Excited States and Dynamics, ACS Symposium Series, ed. M. Gouterman, P. M. Rentzepis and K. D. Straub, American Chemical Society, Washington, DC, 1986, vol. 321, pp. 154-165.

11 D. Gust and T. A. Moore, Mimicking Photosynthesis, Science, 1989, 244, 35-41.

12 K. Maruyama and A. Osuka, A Chemical Approach Toward Photosynthetic Reaction Center,, Pure Appl. Chem., 1990, 62, 1511-1520.

13 P. D. Harvey, Recent Advances in Free and Metalated Multiporphyrin Assemblies and Arrays; a Photophysical Behavior and Energy Transfer Perspective, in The Porphyrin Handbook, ed. K. M. Kadish, K. M. Smith and R. Guilard, Academic Press, San Diego, CA, 2003, vol. 18, ch. 113, pp. 63-250.

14 T. S. Balaban, Tailoring Porphyrins and Chlorins for SelfAssembly in Biomimetic Artificial Antenna Systems, Acc. Chem. Res., 2005, 38, 612-623.

15 L. Flamigni, Photoinduced Processes in Interlocked Structures Containing Porphyrins, J. Photochem. Photobiol., C, 2007, 8, 191-210.

16 V. Balzani, A. Credi and M. Venturi, Photochemical Conversion of Solar Energy, ChemSusChem, 2008, 1, 26-58.

17 M. R. Wasielewski, Self-Assembly Strategies for Integrating Light Harvesting and Charge Separation in Artificial 
Photosynthetic Systems, Acc. Chem. Res., 2009, 42, 19101921.

18 I. A. Maretina, Porphyrin-Ethynyl Arrays: Synthesis, Design, and Application, Russ. J. Gen. Chem., 2009, 79, 1544-1581.

19 N. Aratani and A. Osuka, Synthetic Strategies toward Multiporphyrinic Architectures, in Handbook of Porphyrin Science, ed. K. M. Kadish, K. M. Smith and R. Guilard, World Scientific Publishing Co., Singapore, 2010, vol. 1, ch. 1, pp. 1-132.

20 S. Fukuzumi, Artificial Photosynthetic Systems Composed of Porphyrins and Phthalocyanines, in Handbook of Porphyrin Science, ed. K. M. Kadish, K. M. Smith and R. Guilard, World Scientific Publishing Co., Singapore, 2010, vol. 10, ch. 46, pp. 183-243.

21 P. D. Harvey, C. Stern and R. Guilard, Bio-Inspired Molecular Devices based on Systems Found in Photosynthetic Bacteria, in Handbook of Porphyrin Science, ed. K. M. Kadish, K. M. Smith and R. Guilard, World Scientific Publishing Co., Singapore, 2011, vol. 11, ch. 49, pp. 1-179.

22 D. Gust, T. A. Moore and A. L. Moore, Realizing Artificial Photosynthesis, Faraday Discuss., 2012, 155, 9-26.

23 P. D. Frischmann, K. Mahata and F. Würthner, Powering the Future of Molecular Artificial Photosynthesis with LightHarvesting Metallosupramolecular Dye Assemblies, Chem. Soc. Rev., 2013, 42, 1847-1870.

24 M. E. El-Khouly, S. Fukuzumi and F. D'Souza, Photosynthetic Antenna-Reaction Center Mimicry by Using Boron Dipyrromethene Sensitizers, ChemPhysChem, 2014, 15, 3047.

25 A. Harriman, Artificial Light-Harvesting Arrays for Solar Energy Conversion, Chem. Commun., 2015, 51, 11745-11756.

26 T. Tanaka and A. Osuka, Conjugated Porphyrin Arrays: Synthesis, Properties, and Applications for Functional Materials, Chem. Soc. Rev., 2015, 44, 943-969.

27 M. Rudolf, S. V. Kirner and D. M. Guldi, A Multicomponent Molecular Approach to Artificial Photosynthesis - the Role of Fullerenes and Endohedral Metallofullerenes,, Chem. Soc. Rev., 2016, 45, 612-630.

28 J. Wang, E. Yang, J. R. Diers, D. M. Niedzwiedzki, C. Kirmaier, D. F. Bocian, J. S. Lindsey and D. Holten, Distinct Photophysical and Electronic Characteristics of Strongly Coupled Dyads Containing a Perylene Accessory Pigment and a Porphyrin, Chlorin, or Bacteriochlorin, $J$. Phys. Chem. B, 2013, 117, 9288-9304.

29 E. J. Alexy, J. M. Yuen, V. Chandrashaker, J. R. Diers, C. Kirmaier, D. F. Bocian, D. Holten and J. S. Lindsey, Panchromatic Absorbers for Solar Light-Harvesting, Chem. Commun., 2014, 50, 14512-14515.

30 A. K. Mandal, J. R. Diers, D. M. Niedzwiedzki, G. Hu, R. Liu, E. J. Alexy, J. S. Lindsey, D. F. Bocian and D. Holten, Tailoring Panchromatic Absorption and Excited-State Dynamics of Tetrapyrrole-Chromophore (Bodipy, Rylene) Arrays. The Interplay of Orbital Mixing and Configuration Interaction,, J. Am. Chem. Soc., 2017, 139, 17547-17564.

31 R. W. Wagner, T. E. Johnson and J. S. Lindsey, Soluble Synthetic Multiporphyrin Arrays. 1. Modular Design and Synthesis, J. Am. Chem. Soc., 1996, 118, 11166-11180.
32 M. del Rosario Benites, T. E. Johnson, S. Weghorn, L. Yu, P. D. Rao, J. R. Diers, S. I. Yang, C. Kirmaier, D. F. Bocian, D. Holten and J. S. Lindsey, Synthesis and Properties of Weakly Coupled Dendrimeric Multiporphyrin LightHarvesting Arrays and Hole-Storage Reservoirs, J. Mater. Chem., 2002, 12, 65-80.

33 D. Holten, D. F. Bocian and J. S. Lindsey, Probing Electronic Communication in Covalently Linked Multiporphyrin Arrays. A Guide to the Rational Design of Molecular Photonic Devices, Acc. Chem. Res., 2002, 35, 57-69.

34 G. Hu, R. Liu, E. J. Alexy, A. K. Mandal, D. F. Bocian, D. Holten and J. S. Lindsey, Panchromatic ChromophoreTetrapyrrole Light-Harvesting Arrays Constructed from Bodipy, Perylene, Terrylene, Porphyrin, Chlorin, and Bacteriochlorin Building Blocks, New J. Chem., 2016, 40, 8032-8052.

35 J. S. Lindsey, De Novo Synthesis of Gem-Dialkyl Chlorophyll Analogues for Probing and Emulating our Green World, Chem. Rev., 2015, 115, 6534-6620.

36 D. Gosztola, M. P. Niemczyk and M. R. Wasielewski, Picosecond Molecular Switch Based on Bidirectional Inhibition of Photoinduced Electron Transfer Using Photogenerated Electric Fields, J. Am. Chem. Soc., 1998, 120, 5118-5119.

37 S. Prathapan, S. I. Yang, J. Seth, M. A. Miller, D. F. Bocian, D. Holten and J. S. Lindsey, Synthesis and Excited-State Photodynamics of Perylene-Porphyrin Dyads. 1. Parallel Energy and Charge Transfer via a Diphenylethyne Linker, J. Phys. Chem. B, 2001, 105, 8237-8248.

38 E. Yang, J. Wang, J. R. Diers, D. M. Niedzwiedzki, C. Kirmaier, D. F. Bocian, J. S. Lindsey and D. Holten, Probing Electronic Communication for Efficient LightHarvesting Functionality: Dyads Containing a Common Perylene and a Porphyrin, Chlorin, or Bacteriochlorin, $J$. Phys. Chem. B, 2014, 118, 1630-1647.

39 J. Amanpour, G. Hu, E. J. Alexy, A. K. Mandal, H. S. Kang, J. M. Yuen, J. R. Diers, D. F. Bocian, J. S. Lindsey and D. Holten, Tuning the Electronic Structure and Properties of Perylene-Porphyrin-Perylene Panchromatic Absorbers, $J$. Phys. Chem. A, 2016, 120, 7434-7450.

$40 \mathrm{H}$. Langhals, Synthese von hochreinen PerylenFluoreszenzfarbstoffen in großen Mengen - gezielte Darstellung von Atrop-Isomeren, Chem. Ber., 1985, 118, 4641-4645.

41 H. Langhals, S. Demmig and H. Huber, Rotational Barriers in Perylene Fluorescent Dyes, Spectrochim. Acta, Part A, 1988, 44, 1189-1193.

42 H. Langhals, Cyclic Carboxylic Imide Structures as Structure Elements of High Stability. Novel Developments in Perylene Dye Chemistry, Heterocycles, 1995, 40, 477-500.

43 C. Kirmaier, H.-E. Song, E. K. Yang, J. K. Schwartz, E. Hindin, J. R. Diers, R. S. Loewe, K.-y. Tomizaki, F. Chevalier, L. Ramos, R. R. Birge, D. F. Bocian, J. S. Lindsey and D. Holten, Excited-State Photodynamics of PerylenePorphyrin Dyads 5. Tuning Light-Harvesting Characteristics via Perylene Substituents, Connection 
Motif, and 3-Dimensional Architecture, J. Phys. Chem. B, 2010, 114, 14249-14264.

$44 \mathrm{~J} . \quad$ S. Lindsey, Synthetic Routes to meso-Patterned Porphyrins, Acc. Chem. Res., 2010, 43, 300-311.

45 K.-y. Tomizaki, P. Thamyongkit, R. S. Loewe and J. S. Lindsey, Practical Synthesis of Perylene-Monoimide Building Blocks That Possess Features Appropriate for Use in Porphyrin-Based Light-Harvesting Arrays, Tetrahedron, 2003, 59, 1191-1207.

46 D. P. Arnold, A. W. Johnson and M. Mahendran, Some Reactions of meso-Formyloctaethylporphyrin, J. Chem. Soc., Perkin Trans. 1, 1978, 366-370.

47 H. L. Anderson, Meso-Alkynyl Porphyrins, Tetrahedron Lett., 1992, 33, 1101-1104.

48 V. S.-Y. Lin, S. G. DiMagno and M. J. Therien, Highly Conjugated, Acetylenyl Bridged Porphyrins: New Models for Light-Harvesting Antenna Systems, Science, 1994, 264, 1105-1111.

49 D. P. Arnold and L. J. Nitschinsk, Porphyrin Dimers Linked by Conjugated Butadiynes, Tetrahedron, 1992, 48, 87818792.

50 D. P. Arnold, D. Manno, G. Micocci, A. Serra, A. Tepore and L. Valli, Porphyrin Dimers Linked by a Conjugated Alkyne Bridge: Novel Moieties for the Growth of LangmuirBlodgett Films and Their Applications in Gas Sensors, Langmuir, 1997, 13, 5951-5956.

51 D. P. Arnold and D. A. James, Dimers and Model Monomers of Nickel(II) Octaethylporphyrin Substituted by Conjugated Groups Comprising Combinations of Triple Bonds with Double Bonds and Arenes. 1. Synthesis and Electronic Spectra, J. Org. Chem., 1997, 62, 3460-3469.

52 K. Susumu and M. J. Therien, Design of Diethynyl Porphyrin Derivatives with High Near Infrared Fluorescence Quantum Yields, J. Porphyrins Phthalocyanines, 2015, 19, 205-218.

53 M. Rickhaus, A. V. Jentzsch, L. Tejerina, I. Grübner, M. Jirasek, T. D. W. Claridge and H. L. Anderson, SingleAcetylene Linked Porphyrin Nanorings, J. Am. Chem. Soc., 2017, 139, 16502-16505.

54 R. W. Wagner, T. E. Johnson, F. Li and J. S. Lindsey, Synthesis of Ethyne-Linked or Butadiyne-Linked Porphyrin Arrays Using Mild, Copper-Free, Pd-Mediated Coupling Reactions, J. Org. Chem., 1995, 60, 5266-5273.
55 R. W. Wagner, Y. Ciringh, C. Clausen and J. S. Lindsey, Investigation and Refinement of Palladium-Coupling Conditions for the Synthesis of Diarylethyne-Linked Multiporphyrin Arrays, Chem. Mater., 1999, 11, 2974-2983.

56 M. Taniguchi, A. Balakumar, D. Fan, B. E. McDowell and J. S. Lindsey, Imine-Substituted Dipyrromethanes in the Synthesis of Porphyrins Bearing One or Two Meso Substituents, J. Porphyrins Phthalocyanines, 2005, 9, 554-574.

57 J. K. Laha, S. Dhanalekshmi, M. Taniguchi, A. Ambroise and J. S. Lindsey, A Scalable Synthesis of Meso-Substituted Dipyrromethanes,, Org. Process Res. Dev., 2003, 7, 799-812.

58 C.-H. Lee and J. S. Lindsey, One-Flask Synthesis of MesoSubstituted Dipyrromethanes and Their Application in the Synthesis of Trans-Substituted Porphyrin Building Blocks, Tetrahedron, 1994, 50, 11427-11440.

59 I. Schmidt, J. Jiao, P. Thamyongkit, D. S. Sharada, D. F. Bocian and J. S. Lindsey, Investigation of Stepwise Covalent Synthesis on a Surface Yielding Porphyrin-Based Multicomponent Architectures, J. Org. Chem., 2006, 71, 3033-3050.

60 R. Liu, M. Liu, D. Hood, C.-Y. Chen, C. J. MacNevin, D. Holten and J. S. Lindsey, Chlorophyll-Inspired RedRegion Fluorophores. Building Block Syntheses and Studies in Aqueous Media, Molecules, 2018, 23, 130.

61 M. Gouterman, Study of the Effects of Substitution on the Absorption Spectra of Porphin, J. Chem. Phys., 1959, 30, 1139-1161.

62 M. Gouterman, Spectra of Porphyrins, J. Mol. Spectrosc., 1961, 6, 138-163.

63 M. Gouterman, Optical Spectra and Electronic Structure of Porphyrins and Related Rings, in The Porphyrins, ed. D. Dolphin, Academic Press, New York, 1978, vol. 3, ch. 1, pp. 1-165.

64 D. Kuciauskas, P. A. Liddell, S. Lin, T. E. Johnson, S. J. Weghorn, J. S. Lindsey, A. L. Moore, T. A. Moore and D. Gust, An Artificial Photosynthetic Antenna-Reaction Center Complex, J. Am. Chem. Soc., 1999, 121, 8604-8614.

65 N. Srinivasan, C. A. Haney, J. S. Lindsey, W. Zhang and B. T. Chait, Investigation of MALDI-TOF Mass Spectrometry of Diverse Synthetic Metalloporphyrins, Phthalocyanines, and Multiporphyrin Arrays, J. Porphyrins Phthalocyanines, 1999, 3, 283-291. 